Aalto University

School of Science

Master's Programme in Material Engineering

Matias Koski

\title{
LEAN AND AGILE SUPPLY CHAIN
}

Master's Thesis

Helsinki, Janury $5^{\text {th }} 2016$

Supervisor: $\quad$ Professor Eero Eloranta

Instructor: $\quad$ Simo Nuutinen, M.Sc. 


\begin{tabular}{|c|c|c|}
\hline \multicolumn{3}{|c|}{ Author: Matias Juho Kos } \\
\hline \multicolumn{3}{|c|}{ Subject of the thesis: Lean and Agile Supply Chain } \\
\hline Number of pages: 75 & Date: 15.01 .2016 & Library location: $\mathrm{TU}$ \\
\hline \multicolumn{2}{|c|}{ Professorship: Industrial Management } & Code of professorship: TU-22 \\
\hline \multicolumn{3}{|c|}{ Supervisor: Professor Eero Eloranta } \\
\hline \multicolumn{3}{|c|}{ Instructor: Simo Nuutinen M.Sc } \\
\hline \multicolumn{3}{|c|}{$\begin{array}{l}\text { This thesis examines one of the market leaders in hardware and software business. The } \\
\text { case company is producing several high-tech products for consumers and B2B } \\
\text { customers globally. It has one of the best global supply chains in the world and it can } \\
\text { be kept as a competitive advantage compared to rivals. The objective of this thesis is } \\
\text { to provide insight for the company of its recent control point change in their supply } \\
\text { chain. The company wants to identify and analyze the impact of this change to their } \\
\text { inventory levels and improved availability with less costs. }\end{array}$} \\
\hline \multicolumn{3}{|c|}{$\begin{array}{l}\text { The theoretical part of this paper provides the reader an in-depth review on the drivers } \\
\text { for and challenges of supply chain optimization. The most important topic of literature } \\
\text { review is demand visibility and how it is linked to real-time activation data. An } \\
\text { empirical study of two products of the case company was conducted. Empirical data } \\
\text { was gathered through discussions with colleagues and from the case company's tools } \\
\text { during autumn and winter of } 2013 \text {. }\end{array}$} \\
\hline \multicolumn{3}{|c|}{$\begin{array}{l}\text { The findings of this thesis suggest that in order to achieve lower inventory levels } \\
\text { without risking availability in point-of-sale and to gain faster capital turnover for } \\
\text { customers activation data should be used. From the results can be seen as well how the } \\
\text { bullwhip effect decreased due to a new steering point of supply chain. Furthermore, } \\
\text { The results indicate that activation data should be integrated to sell-in process and } \\
\text { research more widely what have been the benefits. The thesis suggests also that DOS } \\
\text { levels should be defined more accurately for all lifecycles to achieve the best possible } \\
\text { supply steering. }\end{array}$} \\
\hline
\end{tabular}

Keywords: Supply Chain, demand visibility, activation data, inventory level

Publishing language: English 
Perustieteiden korkeakoulu

Master's Programme in Service Management and Engineering

\begin{tabular}{|c|c|c|}
\hline \multicolumn{3}{|c|}{ Tekijä: Matias Juho Koski } \\
\hline \multicolumn{3}{|c|}{ Työn nimi: Kilpailukykyinen ja ketterä toimitusketju } \\
\hline Sivumäärä: 75 & Päiväys: 15.01.2016 & Työn sijainti: TU \\
\hline \multicolumn{2}{|c|}{ Professuuri: Teollisuustalous } & Koodi: TU-22 \\
\hline \multicolumn{3}{|c|}{ Työn valvoja: Professori Eero Eloranta } \\
\hline \multicolumn{3}{|c|}{ Työn ohjaaja: Simo Nuutinen DI } \\
\hline
\end{tabular}

Tämä diplomityö tarkastelee erästä elektroniikka -ja ohjelmistoalan yritystä, joka toimittaa useita erilaisia elektronisia laitteita sekä ohjelmistoja yrityksille ja kuluttajille globaalisti. Yritys on saavuttanut vahvan aseman toimitusketjun hallinnassa, jota voidaan myös pitää yhtenä yrityksen kilpailueduista verrattuna kilpailijoihin. Tämä diplomityö tarkastele miten toimitusketjun ohjauspistettä muuttamalla voidaan vaikuttaa saatavuuteen ja kustannuksiin. Yritys pyrkii työn avulla tuomaan esille kvantitatiivisesti uuden ohjauspisteen hyödyt ja kustannusvaikutukset.

Työn kirjallisuusosio tarjoaa lukijalle kattavasti tietoa tekijöistä, joiden avulla toimitusketjun optimointia pystytään kehittämään sekä merkittävimmistä muuttujista oikean toimitusketjun strategian valinnassa. Diplomityön tavoitteen kannalta, kirjallisuusosion tärkeimmäksi aiheeksi nousee kysynnän näkyvyyden parantaminen, joka voidaan linkittää suoraan aktivointidatan merkittävimpiin hyötyihin logistiikan näkökulmasta. Työn empiirinen tutkimus perustuu kahden tuotteen historiallisen varastotason analysointiin, jotka olivat jaettu kahteen keskenään vertailtavaan ajanjaksoon. Empiirinen aineisto kerättiin yrityksen omista työkaluista ja satunnaisilla keskusteluilla yhtiön työntekijöiden kanssa syksyllä ja talvella 2013.

Tutkielman tuloksista havaitaan, että aktivointidatan käytöllä voidaan saavuttaa merkittävä kilpailuetu alentuneiden varastotasojen, nopeamman pääoman kierron ja paremman saatavuuden ansiosta. Tulokset myös osoittivat, että toimitusketjun uudella ohjauspisteellä voidaan vähentää kysynnän piiskavaikutuksia. Ehdotukseni on, että aktivointi datan hyötyjä tutkitaan vielä lisää ja otetaan paremmin käyttöön myynnin suunnitteluprosessissa. Työssä ehdotetaan lisäksi, että varastotasot pitäisi jatkossa määrittää tarkemmin eri elinkaarenvaiheille paremman saatavuuden turvaamiseksi.

\begin{tabular}{l|l}
\hline Avainsanat: Toimitusketju, kysynnän näkyvyys, & Julkaisukieli: Englanti
\end{tabular} aktivointidata, varastotaso 


\section{ACKNOWLEDGements}

I want to express appreciation to my instructor Simo Nuutinen for the opportunity to write my master thesis in the case company. His guidance, advice and invaluable feedback are highly appreciated. Also, I would like to thank my professor Eero Eloranta for his support and constructive feedback during the work.

Helsinki, 15.01.2016

Matias Koski 
TABLE OF CONTENTS

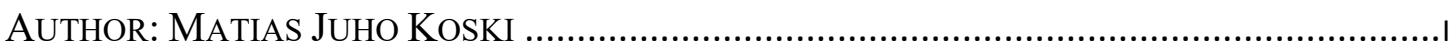

TEKIJÄ: MATIAS JUHO KOSKI ...............................................................................

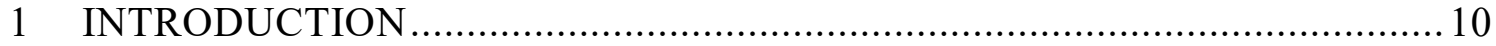

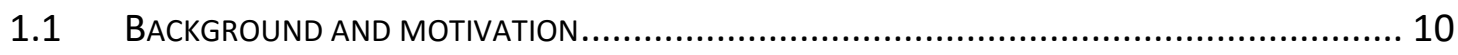

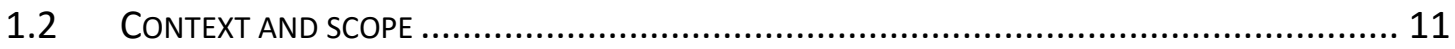

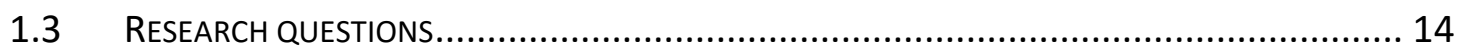

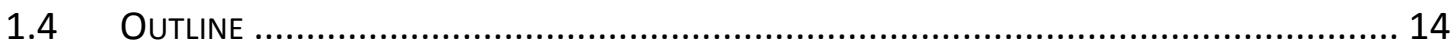

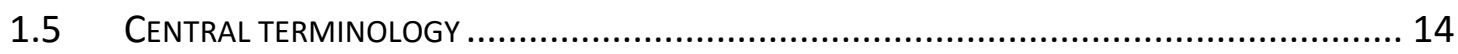

2 SUPPLY CHAIN MANAGEMENT ..................................................... 16

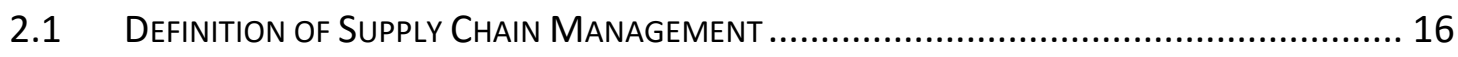

2.1.1 The key purpose of Supply Chain Management is to guarantee availability and in the meantime keep costs in reasonable level ......................................... 17

2.1.2 The impact of lead-time in Supply Chain Management.......................... 18

2.1.3 The relationship between the lead time and the bullwhip effect............. 20

2.1.4 The role of costs in the supply chain ................................................... 22

2.1.5 Customer service and responsiveness in supply chain management ........ 24

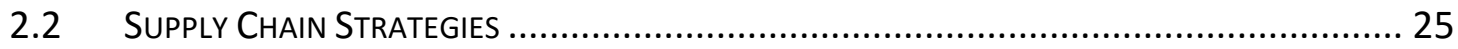

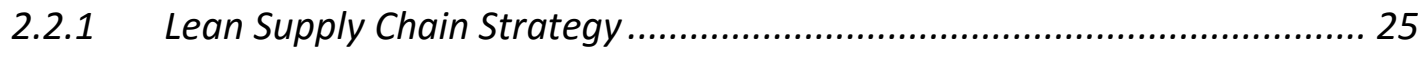

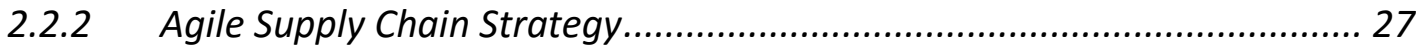

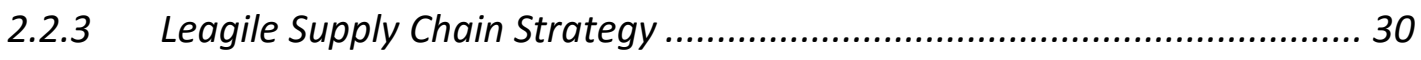

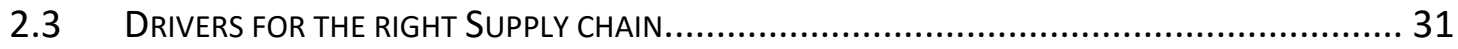

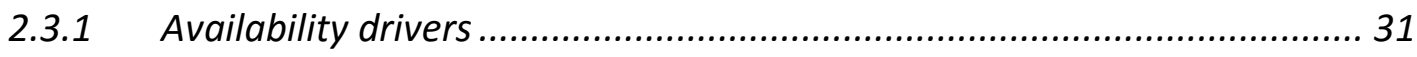

2.3.2 Customer versus product point of view ............................................. 32

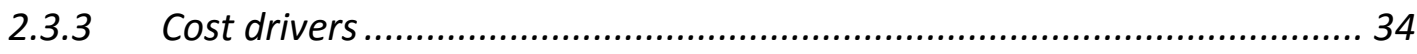

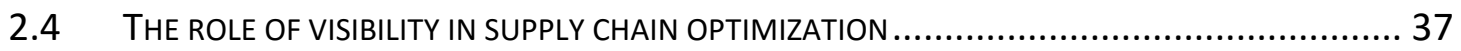

2.4.1 Demand Visibility Point and Order Penetration Point in supply chain

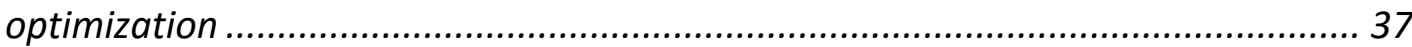




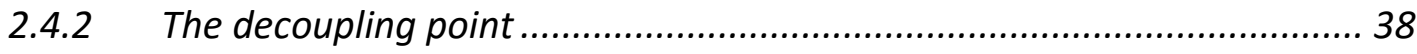

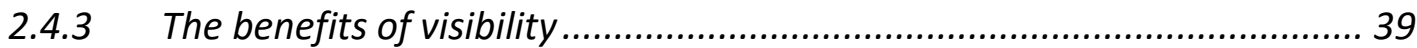

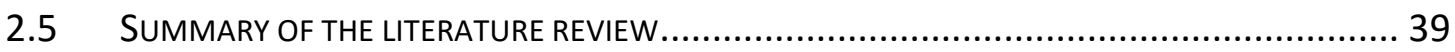

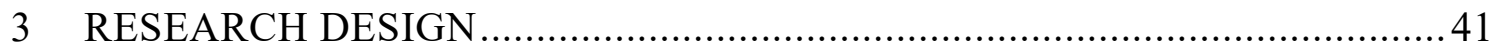

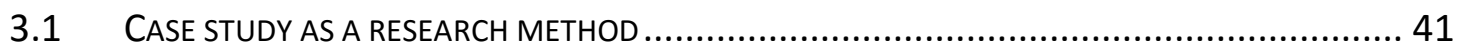

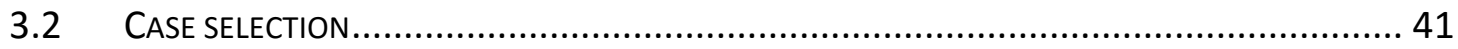

3.2.1 Product A - Low-priced smartphone ............................................... 42

3.2.2 Product B - Mid-priced smartphone ............................................... 42

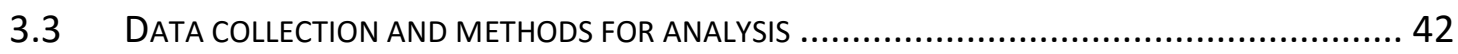

4 CASE REAL TIME ACTIVATION DATA ........................................... 43

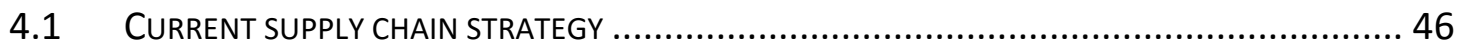

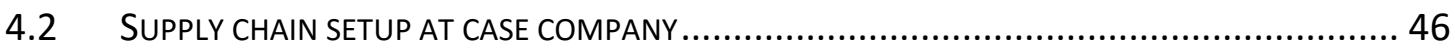

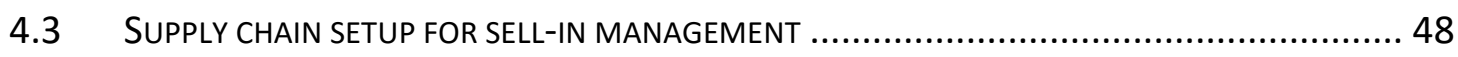

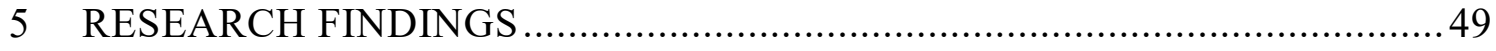

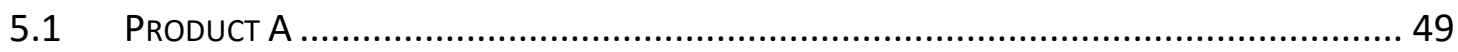

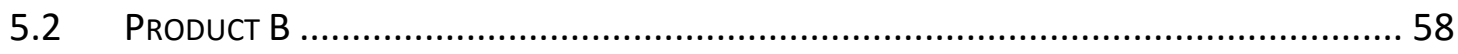

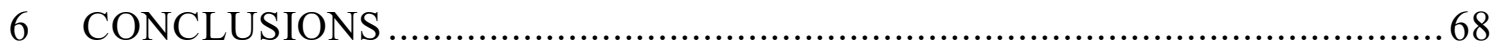

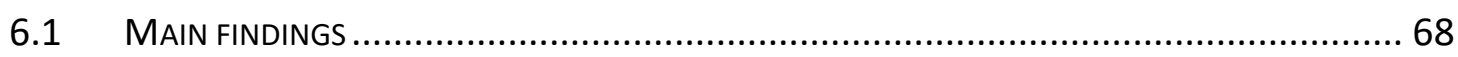

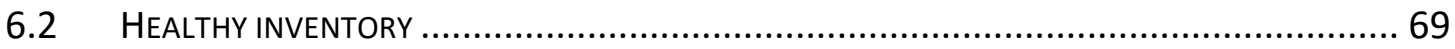

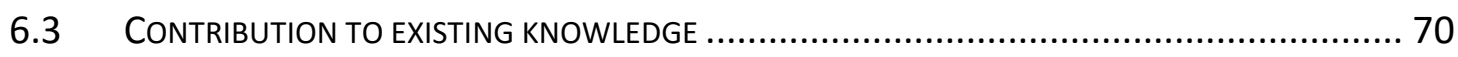

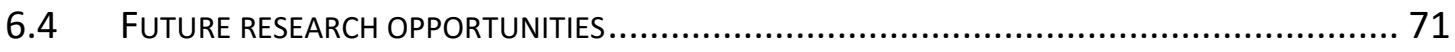

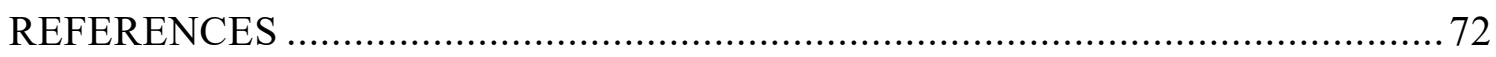




\section{List of figures}

Figure 1: Conflict in the modern-day business environment. ...................................... 12

Figure 2: Sell-in and Sell-out definition flow chart. ............................................. 15

Figure 3: Classification of lead times (Christopher, 1992, 133)............................... 20

Figure 4: Supply chain response matrix (Leanyourcompany.com, 2014). ................... 24

Figure 5: Four principles of lean thinking (Harrison \& van Hoek, 2008)..................... 26

Figure 6: Total waste in manufacturing (Taylor \& Brunt, 2001)............................... 27

Figure 7: Impact of timing in short life-cycle products (Christopher et al, 2004)........ 27

Figure 8: The Foundations for agility in volatile markets (Christopher et al, 2004)..... 28

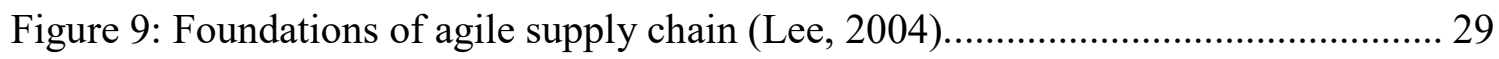

Figure 10: Customer behavior when faced with a stock-out (Christopher, 2011)......... 32

Figure 11: Three different demand chain segments (Collin et al., 2009)...................... 34

Figure 12: How logistics activities drive total logistics costs (Grant et al., 2006)......... 35

Figure 13: The decoupling point (Christopher \& Towill, 2001)................................ 39

Figure 14: The case company's new supply chain strategy................................... 47

Figure 15: Historical inventory vs demand data for product A in Europe..................... 50

Figure 16: Historical days-of-supply data for product A in Europe............................. 51

Figure 17: Healthy inventory share for product $\mathrm{A}$ in different European markets. ........ 51

Figure 18: Weighted average DOS comparison in European markets.......................... 52

Figure 19: Inventory status for product A in Europe. ............................................. 53

Figure 20: Historical inventory data for product A in UK..................................... 54 
Figure 21: Historical inventory data for product A in France.

Figure 22: Healthy inventory share comparison for product A................................. 55

Figure 23: Weighted average DOS comparison in country level................................ 56

Figure 24: Healthy inventory share comparison in customer level (UK). .................... 57

Figure 25: Healthy inventory share comparison in customer level (France). ................ 57

Figure 26: Historical inventory vs demand data for product B in Europe. .................... 59

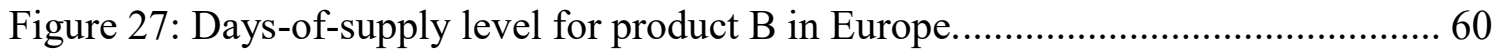

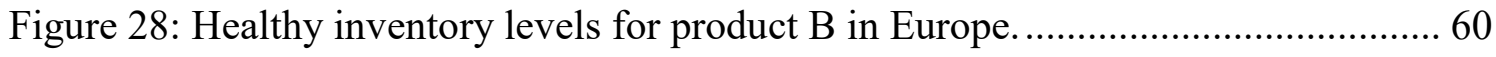

Figure 29: Weighted average DOS comparison in Europe. ....................................... 61

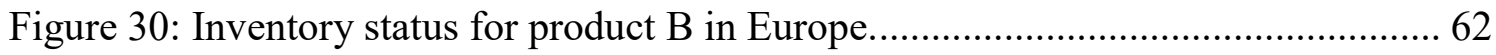

Figure 31: Historical inventory vs demand data for product B in UK........................ 63

Figure 32: Historical inventory vs demand data for product B in France. ...................... 64

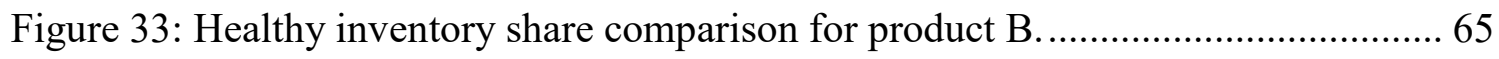

Figure 34: Weighted average DOS comparison in country level............................... 65

Figure 35: Healthy inventory share comparison in customer level (UK). ................... 66

Figure 36: Healthy inventory share comparison in customer level (France)................. 67 


\section{List of Tables}

Table 1: Functional Versus Innovative products. (Fisher, 1997)................................ 33

Table 2: Case company's supply chain strategies for different products...................... 44

Table 3: Characteristics of business environment and their implications..................... 45

Table 4: Cost savings and end results by product. ................................................. 70 


\section{List of Abbreviations}

\begin{tabular}{ll} 
ABC & Activity Based Costing \\
DOS & Days of Supply \\
DPP & Direct Product Profitability \\
FMCG & Fast Moving Consumer Goods \\
FMS & Flexible Manufacturing Systems \\
FOB & Free On Board \\
Leagile & Lean and Agile \\
OOS & Out of Stock \\
OTD & On Time Delivery \\
PDP & Product Delivery Process \\
PLC & Pupply Chain Management \\
SCC & Product Life Cycle \\
\hline
\end{tabular}




\section{INTRODUCTION}

In this chapter background and motivation of the study which give an overview about supply chain is firstly introduced. Thereafter context and scope for this paper are presented to describe the challenges and characteristics of case company's business. A research question of thesis is illustrated in the introduction part as well to tell reader what is the aim of the thesis. In the end of this chapter is shortly illustrated outline of the thesis and defined the most important terminologies.

\subsection{Background and motivation}

Supply Chain is described as a chain linking each element from customer and supplier through manufacturing and services so that flow of information, money and material can be effectively managed to meet the business requirement (Stevens, 1987).

In today's uncertain and fast moving business environment Supply Chain Management (SCM) is playing an important role in the success of a firm's product and market growth strategy (Sharifi, Ismail, Qiu, Tavani, 2013). SCM assists companies in integrating their business by collaborating with other value chain partners to meet the unpredictable demand of end user. A fully integrated supply chain or solid supply engineered to cope with uncertainty, can profitably fulfill customer demand, while non-integrated manufacturing process, non-integrated distribution process and amiss relationships with customers and suppliers are the key factors of business failure for trading companies (Agarwal, Shankar, Tiwari, 2005)

Supply chain strategies can be divided roughly in three different categories. One is lean supply chain strategy which is widely used in those markets where cost is the primary order winning criteria. Second strategy is agile supply chain which is used in volatile markets where the order winner is availability. This has led to the emergence of the agile paradigm typified by quick response and similar initiatives. (Aitken, Christopher, Towill, 2002). Third category is a combination of lean and agile supply chain which combines the 
parts of both worlds. It is also called leagile supply chain and many successful companies are using it. In this concept cost effectiveness stands out when compared to lean paradigm and quick response time to volatile demand when compared to agile paradigm (Christopher and Towill, 2001).

Sometimes uncertainty is impossible to remove from supply chain due to the type of product involved. Therefore risks need to be managed and mitigated by using suitable supply chain. Like in the case company's markets products are mostly remarkably innovative then, by its very nature, its demand will be unpredictable. Thus, specific supply chains are faced with a situation where company has to face the fact that markets are uncertain but they need to develop a strategy that enables them still to match supply and demand (Mason-Jones, Naylor, Towill, 2000).

\subsection{Context and scope}

The case company in this thesis is corporation $\mathrm{X}$, which is one of the market leaders in the IT sector. In $2012 X^{\prime}$ 's revenue was approximately 73 billion and it employed about 97000 people globally. It develops, manufactures, licenses, supports and sells computer software, consumer electronics, personal computers and services. In the case company's supply chain work globally approximately 32000 people and it includes 9 factories around the globe. This thesis is outlined to cover the case company's mobile devices supply chain in Europe. To help reader to understand how big volumes are moving through the chain, only Europe sold 11,3 million smart phones during 2013.

This thesis is motivated by the appeal to use real time channel inventory and demand data to operate supply chain more flexibly without losing leanness features. The intuition exists that lean and agile supply chain is possible to gain with a new supply chain control point. When considering supply chain optimization, all the relevant data of the supply chain should be included in decision making. For example with real time demand data it is possible to steer goods to right country/customer, in the right time and keep inventories in healthy level. In this thesis healthy inventory can be described by using end-to-end DOS level that reflects all that volumes which is shipped from factory but is not taken into use 
by customers. Depending on the product end-to-end DOS target should be usually between 70 and 80 days in Europe. This varies a bit for each product as supply chains are different but based on empirical evidence no overstocks or stock outs occur when DOS is between 70 and 80 days.

The business environment in many industries has become characterized by increased unpredictability due to short product life cycles, lack of brand loyalty, continuously changing trends and competitive pressures. Therefore, business focus has moved to the speed of response to serve customers while constantly optimizing total cost of supply chain. As a result of this change, the need of agile and lean supply chain is a necessity in today's business model for a company operating in telecommunication industry. Balancing between supply chain costs and customer service level is a day-to-day routine in order to perform in competitive markets. This conflict is presented in figure 1 . Christopher (1992) also notes wisely; pioneer companies understand that the supply chain as a whole must be made more competitive through the value it adds and the total costs that it reduces overall.

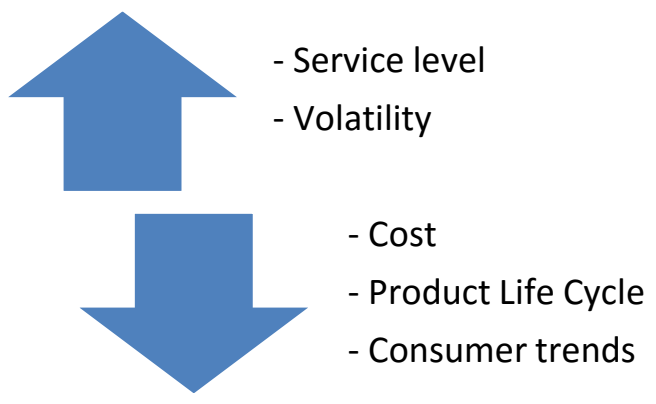

Figure 1: Conflict in the modern-day business environment.

The scope for this study is well explained in the following dilemma: "The most challenging operations issue is how to offer as good service level as possible to the customer and at the same time reduce costs". The definition of value from the customer's point of view is dynamic concept and it is continuously changing over the time in the telecommunication industry. At the moment, the speed of the supply chain in delivering value to the customer has become increasingly important i.e. customers are not willing to 
wait the product anymore. This might have led to the development of different kinds of supply chain strategies like the agile supply chain.

A flexible and responsive supply chain is only sustainable if its total costs are kept under control. Hence realizing the different cost drivers and total costs of end-to-end supply chain is vital. In other words, understanding the overall company strategy and the key cost-trade-offs in the organization is important when developing a right supply chain strategy. As Grant et al (2006) note, the target of logistics is to support the company's customer service goals in a value-adding, effective and efficient manner. By approaching supply chain strategy selection from service level and total cost point of view, right strategy can be chosen quite easily.

One key principle in supply chain optimization is lead time and therefore the effect of lead time in supply chain should be scrutinized in this thesis. All in all, the different lead times between stakeholders in supply chain, define the agility of the whole chain. Furthermore, inventory management literature survey determines the impact of lead time on inventoryholding and related costs. When considering the impact of lead time in the supply chain it should be taken in consideration that lead time is always trade-off between total costs and the responsiveness of the chain. Because of this, the definition of the impact of lead time could be used in the decision-making process of a company.

According to Aberdeen research (2006), Best in Class companies, when using in demand planning, achieve accuracy of $60 \%$ or greater in product family level. This highlights the fact that the need for flexibility and responsiveness is unavoidable to the market environment of fast-paced industries where product life cycles are short and demand volatility is high. So adapting the supply chain is a requirement to staying in business. Hopp and Spearman (2001) also note, when markets and trends change, companies should not only consider the potential to improve profits, but also the need to avoid lost profits. Hence the motivation for this thesis is well justified. By optimizing the sell-in, the improved flexibility of the supply chain holds significant potential in improving profits due to lower inventory levels and due to needing less price reductions during the products life cycle. In this case sell-in can be defined as sold goods to distributors and operators. 


\subsection{Research questions}

Thus, this thesis aims to answer the following research question:

- How the real time activation data and channel inventory information can be used to improve both sell-in and sell-out optimization in increasing customer's effective capital employed due to lower channel inventory

This question will be addressed through theoretical and empirical study.

\subsection{Outline}

The thesis consists of four parts: Thesis starts with introduction that explains background of the study, context, scope, central terminology and research questions. Then there is a literature review that gives theoretical review to supply chain management and lays solid ground for the empirical study. Before empirical study is illustrated shortly research design and in the end of the thesis are presented conclusions and recommendations based on findings from the empirical study.

\subsection{Central terminology}

Lean Supply Chain is a term referring to Supply Chain where all waste i.e. non-value added activities which do not give any value for customer are eliminated. Main benefits are low costs and high quality. In other words leanness in a supply chain maximizes earnings through cost reduction (Aitken et al., 2002)

Agile Supply Chain is widely used with fast moving consumer goods. It is developed for volatile and turbulent marketplace where availability is the crucial factor i.e. due to long lead-times customers chooses competitor's products. Agile Supply Chain also maximizes profit through providing exactly what the customer requires. (Christopher, 2011).

Leagile Supply Chain is a concept where best parts from lean and agile supply chain are combined. The leagile supply chain enables the upstream part of the chain to be cost- 
effective and the downstream part to achieve high service levels in a turbulent market (Christopher and Towill, 2001).

Bullwhip effect is a term used to describe an order fluctuation between the factory and end customers. Moving up the supply chain from customer level to raw-materials suppliers, each supply chain participant has a stronger observed variation in demand. The most common sources of the bullwhip effect are: demand signal processing, order batching, price variation and rationing game (Lee et al., 1997).

Stock-out is a term used to refer a situation where no stock was available to fulfill an order from end user. Especially on the FMCG industry stock-outs might be very costly as customers are not usually brand loyal and due to poor availability they might end up to buy competitor's product. In some context Out of Stock (OOS) is also used instead of Stock-out (Vitasek, 2006).

Sell-in is a less used term to describe how many units are sold to retail shops by the manufacturer for re-sale to end users (Vitasek, 2006). This is a phase of sell-through where the manufacturer works with its resellers to fill their for sale channel inventory.

Sell-out is a term referring to sold units from retail shops to end users. This is a phase of sell-through where demand is establishing i.e. sell-out is describing the real demand of end users (Vitasek, 2006).

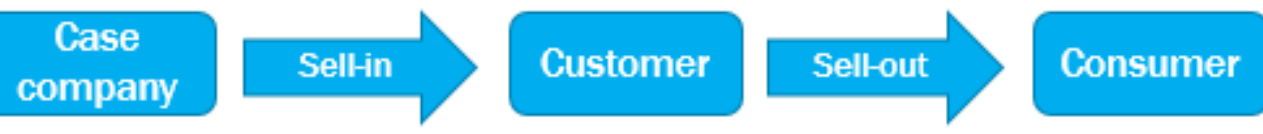

Figure 2: Sell-in and Sell-out definition flow chart. 


\section{Supply Chain Management}

In this chapter, I will first introduce relevant basic theories in the area of Supply Chain Management. Thereafter, three different supply chain strategies are defined to help to understand that one strategy does not fit all markets. Supply chain strategies are linked to drivers in the next sub-chapter to illustrate for example how cost and availability variables affect to decision making. Later in the literature review demand visibility is defined and its various benefits in supply chain optimization. In the end of the chapter one can find a summarized literature review and explanation where and how the new control point in supply chain should work.

\subsection{Definition of Supply Chain Management}

Supply Chain Management is already a very old concept and earliest allusions are from 1960s according to Huan et al. (2004). The research of SCM was quite small in the beginning of 1960s and 1970s but in 1980s relevant studies increased and had dramatic increase in the 1990s (Huan, 2004). As Cooper et al (1997) have pointed out, one reason for dramatically increasing studies related to SCM is that top leaders had recognized the significance of having efficient supply chains to create competitive advantages.

Supply Chain Management is a very diversely used term in academic and business literature. Hoover et al. (2001) have showed that SCM incorporates key ideas from lean manufacturing and supplier management, and extends the scope to distribution. The purpose of SCM is to develop the efficiency of the product delivery process from material suppliers all the way to the end customer i.e. the right product at the right time to the right end customer with a minimum of handling points and buffering. This definition is apposite for this study as the approach of the research is to find a new way to optimize sell-in and sell-out in regional level by using real time activation data from devices. 
As Agarwal et al. (2005) note, companies are continuously paying attention in responding to the customer demand for maintaining a competitive advantage over their rivals. SCM has gained attention as it focuses on material, information and cash flows from vendors to customers or vice-versa.

To help reader to understand basics of Supply Chain Management, its principles are presented shortly in this chapter. The chapter consists of four subtitles that give a good basic understanding about key drivers of SCM. The importance of minimizing the costs during the whole chain is explained in the first subtitle. The second subtitle illustrates the impact of lead-time in SCM. The third subtitle describes how lead time influences to the bullwhip effect. The link between inventory management and lead time is explained in the fourth subtitle. The fifth subtitle illustrates how lead times affect customer service.

\subsubsection{The key purpose of Supply Chain Management is to guarantee availability and in the meantime keep costs in reasonable level}

In the literature there can be found many different definitions of SCM. The definitions vary widely but in general level the focus is always to ship products with minimum costs and achieving reasonable service level to customers. Shapiro (2001) notes concise that traditional objective of SCM is to minimize the total Supply Chain Cost (SCC) to meet fixed and given demand. For example total costs might include the following:

- Facility investment costs

- Indirect/direct distribution cost

- Indirect/direct manufacturing cost

- Inventory holding cost

- Outbound/inbound transportation cost

- Raw material and other acquisition costs

Simchi-Levy et al (2000) describe SCM as a set of approaches utilized to efficiently integrate suppliers, manufactures, warehouses and stores, so that merchandise is produced 
and distributed at the right amounts, to the right locations and at the right time, in order to minimize system wide costs while satisfying service level requirements. The objective of SCM is to improve operations management across functional boundaries in the supply chain. Therefore, one purpose of SCM is to reduce the supply chains total costs and to improve the quality and service to its end customers (Berry and Naim, 1996).

Ross (1998) notes wisely, that operating costs of each of the logistics functions were inversely proportional and that management should aspire to minimize the total costs of the whole logistics chain, rather than focusing on reducing the costs of one or two specific logistics functions i.e. management should avoid sub-optimization in the supply chain. Therefore, reducing costs in only one part of the supply chain could lead to a raised total cost for the chain. This is the opposite approach to traditional accounting, which allocates costs to a few volume drivers, often based on functional organization dimensions as Collin (2003) states in his study.

What comes to availability point of view it should be taken into account same time than costs. As the case company's products have short life cycles, unstable demand and poor planning accuracy, those things cause problems when company try to achieve good availability and keep costs in reasonable level. This thesis approach this issue with Fisher's (1997) frame work where products can be divided into two different groups (innovative and functional products) and right supply chain will be chosen based on this categorization. Fisher's theory is explained more widely further in chapter 2.3.

\subsubsection{The impact of lead-time in Supply Chain Management}

One of the key factors in designing right SCM for customers is lead-time. As earlier is noted, in this paper the key purpose of the SCM is to guarantee availability and keep costs in reasonable level. Costs is not everything because a company with low costs could still be in a not desired position when its customers are disconnected, because this carries the risk of losing customers due to low performance. 
Agarwal et al (2007) and Slack et al. (2010) define the lead time as the elapsed time from customer's order to delivery of the goods. In customers point of view the lead time is usually defined in the same way. This is good to keep in mind as only thing what the customers are interested in is the lead time of their order. Management of time and lead times can be very crucial advantage in the competitive marketplace where there is little brand loyalty. Hopp and Spearman (2001) define lead time in the manufacturing context as the time allowed for production of an item on particular line. Whereas, Silver et al $(1998,48)$ define lead time as the time that elapses from the moment an order is placed on the system until the product is available on the shelf for end user. On the whole, in literature there are several different definitions for lead time and in various contexts it is referred as follows:

- Manufacturing lead time, which describes how much time is taken in the manufacturing process

- Inbound lead time, which refers in general to the delivery lead time from order placement to company receiving the goods

- Outbound lead time, referring usually to the lead time from company to its firsttier customers

- End-to-end lead time, referring to the total time in the supply chain i.e. from customer making the order to receiving the goods

In the literature lead time is explained in some context as a response time of the entire supply chain. The most important definition for this study is the end-to-end lead time, which is the widest concept of above mentioned definitions. By understanding total lead time in the supply chain it is easy to focus on its bottle necks. According to Christopher (2001) end-to-end lead time can be divided into five components and 13 subcomponents. See the figure 3 below. 


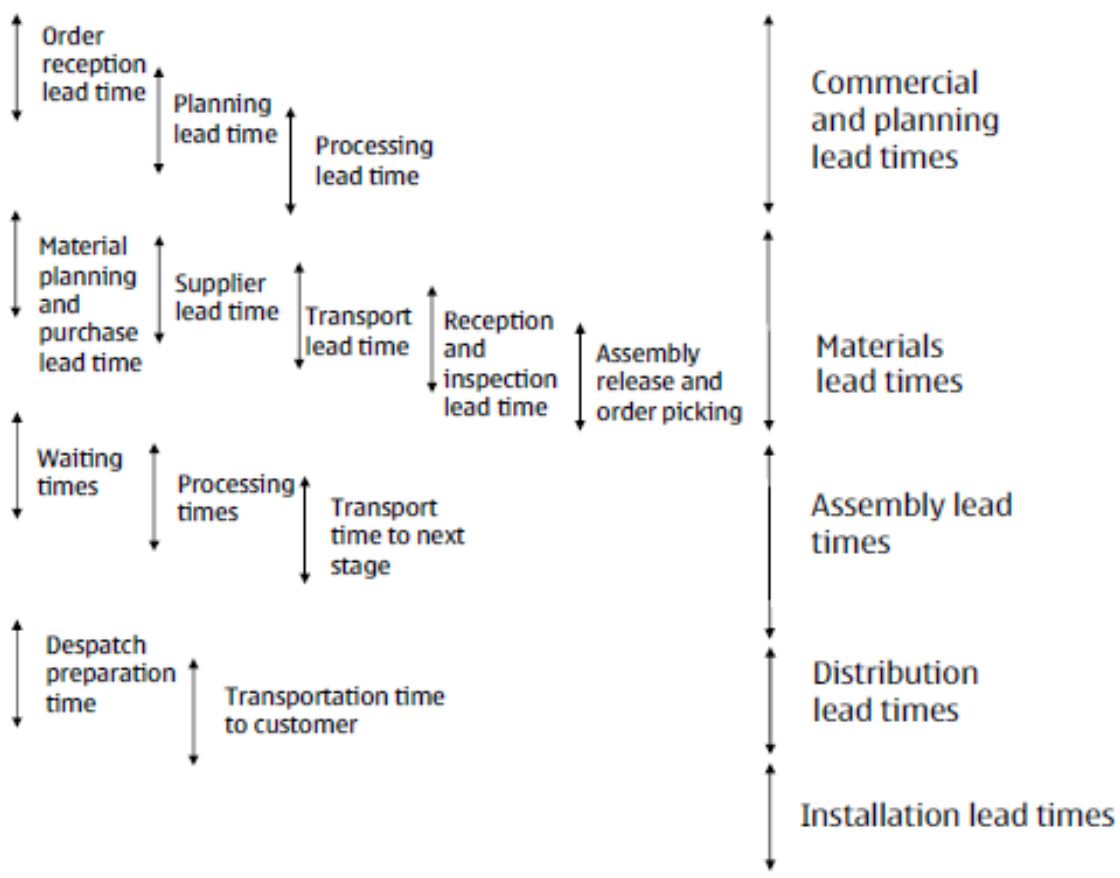

Figure 3: Classification of lead times (Christopher, 1992, 133).

\subsubsection{The relationship between the lead time and the bullwhip effect}

Maybe one of the most well-known terms of supply chain management is the bullwhip effect. Lee et al (1997) describes that bullwhip effect is a phenomenon where orders to the supplier tend to have larger variance than sales to the customer i.e. it can be defined also as demand distortion which propagates upstream in an amplified form (variance amplification). Whereas, Hopp and Spearman (2001) note that poor channel management leads to inefficiency in the chain: inventory levels are incorrect and at the wrong place in the supply chain, but also to the amplification of demand fluctuations from the bottom of the chain to the top (i.e. bullwhip effect). Several large-scale enterprises have been recognized the bullwhip effect in their market. For example, Procter \& Gamble found that fluctuations in orders from the distributor cannot be explained by consumer demand fluctuations alone. Also Hewlett-Packard noted that in the printer division the orders from resellers had much stronger swing and fluctuation than real customer demands (Lee et al, 
1997). Same authors have identified lead times as one instigator of the bullwhip effect, others are batch ordering, demand forecasting, price variations and supply shortages (ibid).

According to Chen et al. (2000) increase in variability from the retailer to the manufacturer is an increasing function of three parameters of which lead time is one. Furthermore, authors have also found link between lead times and demand forecasting and they point out that with longer lead times the amount of data used in demand forecasting must increase in order to attenuate the bullwhip effect. Hence, literature and past research has demonstrated that long lead times and information distortion have a clear connection in the supply chain, which might occur as a poor customer service level due to lack of availability or inflation of inventories.

As it has earlier been noted, variability has a deplorable influence in the supply chain and it should be minimized with inventory, capacity or time. Hence, the bullwhip effect causes negative consequences, like inefficient use of capacity, excessive work-in-progress, expediting costs and long lead times or even customer backlogs (Hopp and Spearman, 2001). Gaming behavior is one cause of the bullwhip effect. It is also driven by lead times; for example, when an item has a long lead time, there is a risk that retailer overestimates requirements because if demand leaps, it will be difficult to obtain the items on time. Thus long lead times cause inflated ordering and the amplification of information distortion. Eventually it can be stated that lead time drives the bullwhip effect through of its several acknowledged causes, and it can be referred as one of main components to the effect (Hopp and Spearman, 2001).

Hopp and Spearman (2001) also emphasize that safety stock and safety lead time can be used to protect against the volatility in the volume and timing of supply and demand. The definition of safety stocks reflect the inventory that protects against stock outs due to fluctuations of demand and supply. Hence, safety stock can improve customer service and responsiveness (ibid).

In general, the long lead time is directly proportional to amount of carried stock (Hopp \& Spearman, 2001), thus longer lead times increase inventory-holding costs, risk of stock outs and costs from obsolescence. Longer lead times can be seen uncertainty in supply 
chain because order has to be placed much before company has visibility to real demand i.e. company has to make forecasts to guarantee good availability for the customer. Thus, plans are always inaccurate so this results in increased inventories in the form of safety stock to buffer against uncertainty. Due to increased inventories the risk of obsolescence also grows and in the worst case there might be excess stock that has to be scrapped in the future.

The case company is one of the best in planning the demand but still forecast inaccuracy is a significant cost driver for the company (Nokia Corporation, 2009). One way to decrease inventory levels but still keep short lead times is to create capacity buffers i.e. production capacity can be reserved for possible upsides. This can be done by keeping utilization rate low in order to have a better ability to respond to an increase in demand (Hopp \& Spearman, 2001). Before capacity reservations the cost of reserving capacity should be calculated against the cost of holding inventory to achieve the best possible solution to ensure availability.

\subsubsection{The role of costs in the supply chain}

As it was earlier noted, there is a clear link in the supply chain between lead times and inventory costs. Inventory management literature and the key factors of inventory holding costs are commonly known and a part of general business practice. Nevertheless, the valuation of inventory carrying costs in various companies depends on different elements,

such as what is the return requirement for the time value of money and valuation of committed capital of inventory. 
Shapiro (2001) has pointed out that the inventory of raw materials, intermediate and finished products are in a significant role in efficient supply chain planning. Inventoryholding costs, which include capital costs, stock out costs and depreciation costs due to obsolescence, can be a major component of total supply chain cost. In the literature there is also several other good definitions for inventory-holding costs and Hoover et al. (2001) definitely describe it very concisely. They suggest the following structure:

- administration (stock keeping, IT costs etc.)

- capital costs (For raw materials, finished goods, work-in-progress)

- fixed assets (space, equipment)

- insurance

- lost sales

- obsolescence (price erosion, scrap, deterioration)

- personnel costs (inventory related labor)

Price erosion is a consequence of the learning curve in manufacturing and in product development i.e. the erosion of price of old products or versions upon the introduction of a new product. Instead of offering customer price protection against price erosion, most advanced suppliers try to shift focus and prevent inventories from building up (ibid). The authors have found a connection between lead time, channel visibility and price erosion by stating that value innovation opportunity exists in developing supply chain management methods that provide shorter order fulfillment lead time, for example, they reduce the impact of price erosion for all the parties in the supply chain. This price erosion is an extremely important factor in telecommunication industry where magnitude of price erosion has been between 20 and 30 percent per year (ibid). This is caused by rapidly developing technology and short product life cycles. Hence by reducing lead times in different part of the chain or increasing demand visibility it is possible to achieve more responsive supply chain with lower inventory levels and total costs. 


\subsubsection{Customer service and responsiveness in supply chain management}

According to Hopp and Spearman (2001) impact of lead time in the customer service simply means satisfying customer needs with quick response and on-time deliveries. Customer service can be defined in operations' context as the fraction of demands that are satisfied on time. This customer service level can be also measured by On Time Delivery metrics (OTD) which describes how many shipments are delivered on the same or next day as defined by customer. It is explained in the previous section how lead times contribute to the inventory levels and how this impacts the customer service and responsiveness of the supply chain.

Christopher (2011) notes that customers in every market want ever shorter lead times; product availability will overcome brand or suppliers loyalty. For example if customer's preferred brand is not available and a substitute is, then the likelihood is a lost sale.

In general, customer service level is described from the end user's point of view and is related to the lead time of the entire supply chain. Hence response time to the end user is sum of all the lead times in the whole supply chain. This can be presented with a matrix that illustrates the determining lead time constraints for a particular process. See figure 4.

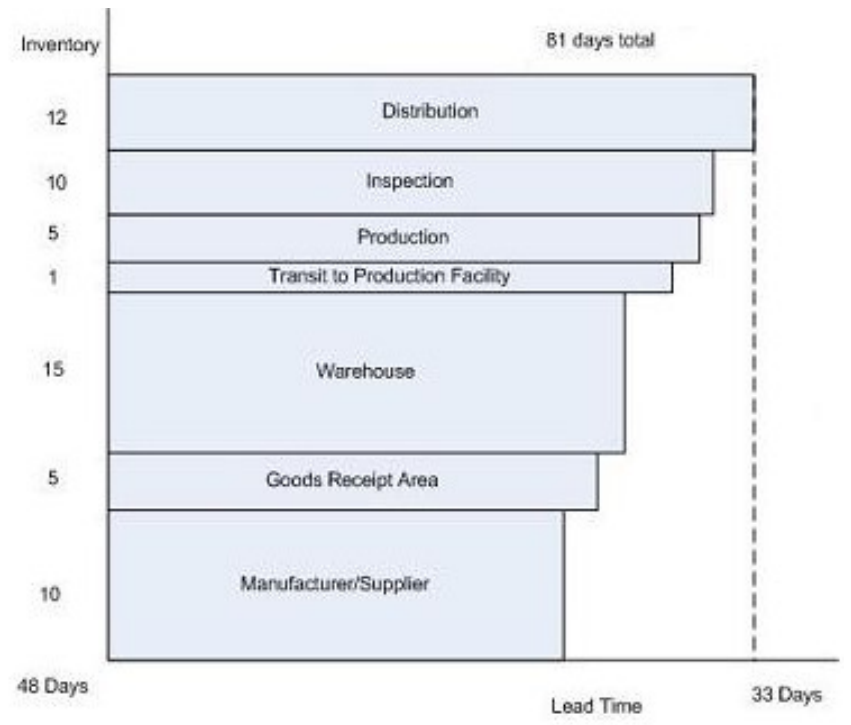

Figure 4: Supply chain response matrix (Leanyourcompany.com, 2014). 
In figure 4 an example is presented of the cumulative lead time for the entire supply chain. The horizontal measurements illustrate the lead times for each part of the chain, while the vertical axis shows the average amount of standing inventory in days. The cumulative lead time is 33 days plus the inventory which is 48 days of supply (DOS) i.e. the total response time is 81 days for this system.

This method is originally presented by Taylor and Brunt (2001) and they describe the response time of the supply chain as the sum of lead time and inventory. By understanding specific inventories and lead times in the supply chain it is easy to focus the improvement activities to "pain points" and reduce total response time of the whole chain to improve the customer service level due to better availability.

\subsection{Supply Chain Strategies}

As Christopher and Towil (2001) succinctly states, the most important elements in attempting to establish a new supply chain strategy are to fully understand marketplace and how to satisfy customer's need. Different products and customers need different kinds of Supply Chain Strategies and as earlier is noted "one size does not fit for all". In this chapter is illustrated three different strategies and their optimal business environments. Further in this thesis is explained what are the drivers in choosing the right supply chain strategy for a company.

\subsubsection{Lean Supply Chain Strategy}

The main focus in the lean approach is elimination of all waste or so called "muda" i.e. Lean aims to increase value while eliminating waste in processes and in work methods. Kent \& Attri (2007) define Lean as a philosophy that accentuates minimizing the amount of resources used in the various activities of a company. It includes identifying and eliminating non-value-adding activities aka "muda" in all activities (for example in design work, production, supply chain and dealing with customers). According to Aitken et al (2002) lean is doing more with less and it is often linked to zero inventory and just-in- 
time approach. Harrison \& van Hoek (2008) describe that lean thinking is a cyclic route to seeking perfection by eliminating possible waste from the system. Waste is defined as non-value-adding activities (e.g. delay, inspect, store and transport). The basic idea is that end-customer should not pay for the cost, time and quality penalties of wasteful process in the supply chain. Four basic principles are needed to achieve the fifth principle, perfection. These five elements are presented in figure 5 .

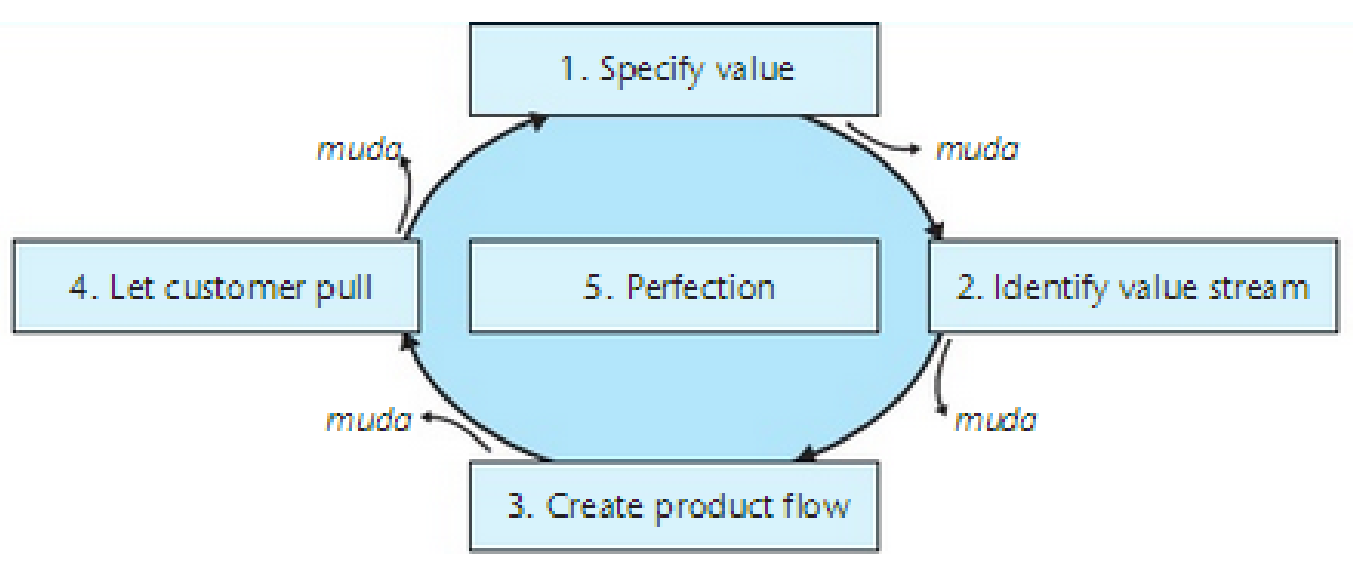

Figure 5: Four principles of lean thinking (Harrison \& van Hoek, 2008).

Taylor \& Brunt's (2001) demonstrate very clearly how different actions are value adding or non-value-adding in the manufacturing context. Like earlier has been noted the lean approach aims to eliminate waste and in figure 6 it is presented that different kinds of storing and moving does not add any value to the process. Although agile strategy is different than lean strategy, they share a same target according to Goldsby et al. (2006): fulfilling customer demands at lowest total cost as possible. In practice lean thinking works best in environment where there is high volumes, stable demand and low variety, whereas the agile strategy works in the opposite environment (Grant et al, 2006). This agile strategy is described in the next sub-chapter. 


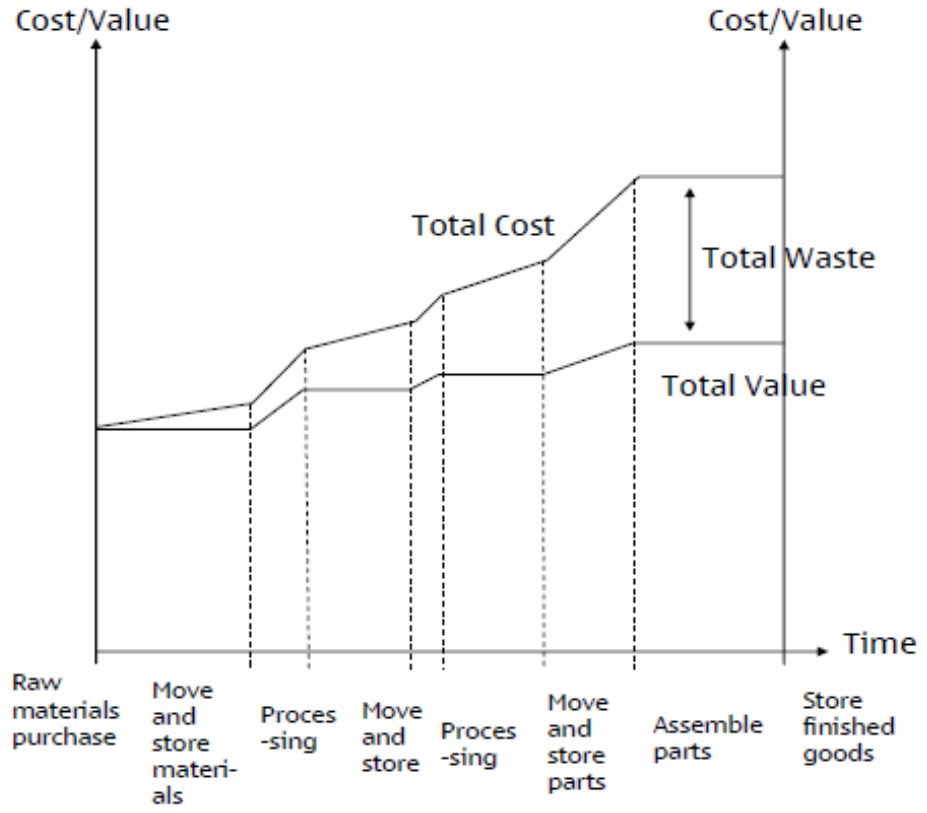

Figure 6: Total waste in manufacturing (Taylor \& Brunt, 2001).

\subsubsection{Agile Supply Chain Strategy}

In these short life-cycle markets, being able to spot trends quickly and to translate them into ready products in the shortest possible time has become a pre-requisite for success. This can be also explained by bringing the product late to the market and then there is higher risk for obsolescence and less time to make profit. See figure 7.

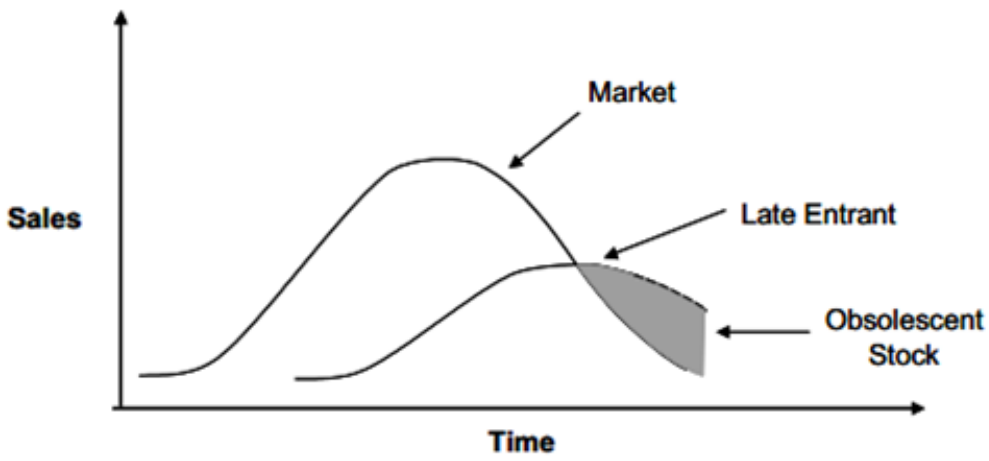

Figure 7: Impact of timing in short life-cycle products (Christopher et al, 2004). 
In some market environments uncertainty is impossible to remove from the supply chain due to the type of product/customer involved. For example, if a product has short lifecycle then by its inherent nature its demand will be unforeseeable. Therefore, specific supply chains are faced with the situation where they have to adapt for uncertainty and at the same time they need to develop a strategy where supply still meets demand (Christopher \& Towill, 2001).

In the literature all authors do not define agility in the same way. According to Aitken et al. (2002), the origin of agility as a business concept lies in flexible manufacturing systems (FMS) and flexibility should be considered as a key characteristic of an agile organization. Lee (2004) describes agility as the ability to respond quickly to short term changes in demand or in supply. Fliedner and Vokurka (1997) define agility as an ability to produce a wide range of low-cost, high quality products with short lead times in varying lot sizes, built to individual customer specification. Whereas Mason-Jones et al. (2000) suggest agility means using market knowledge and virtual corporation to exploit profitable opportunities in a volatile market place. Christopher et al. (2004) argue that agile supply chain needs the following four key dimensions to succeed in competing markets. See figure 8 .

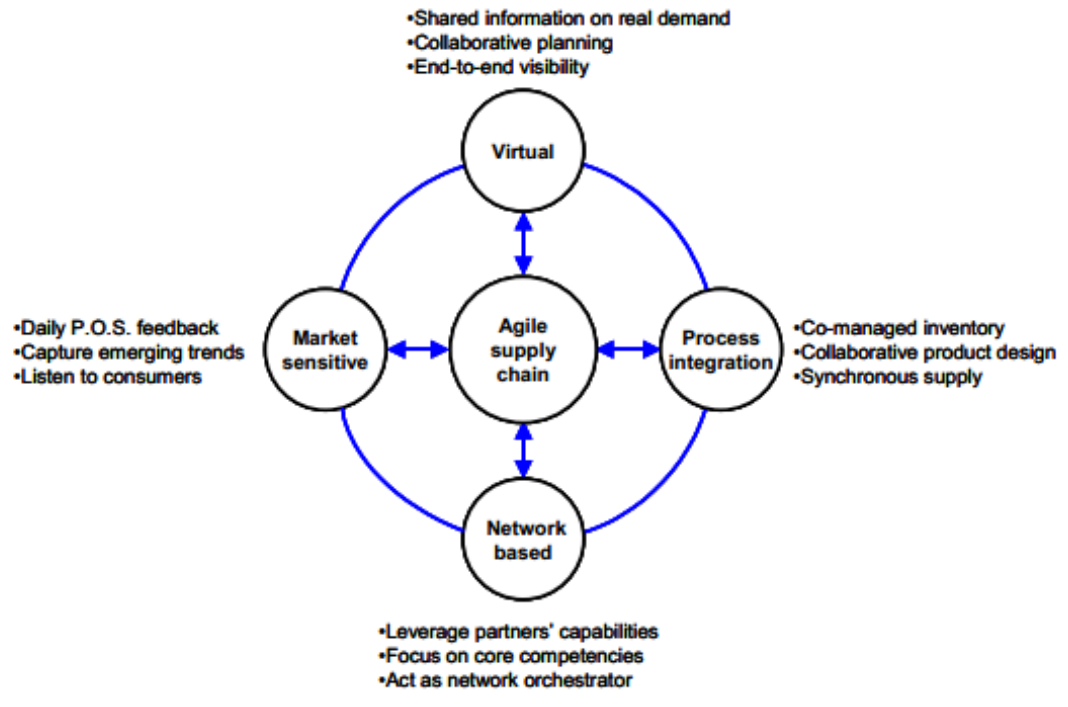

Figure 8: The Foundations for agility in volatile markets (Christopher et al, 2004). 
In the figure it can be seen how market sensitiveness is linked to agile supply chain. Market sensitiveness is mostly based on point-of-sale data analyses and the data is used to determine replenishment requirements when the intention is to continue to make the product available. Beyond point-of-sale data are real consumers and identifying their preferences and their changing requirements should be a continuing priority. Virtual integration refers to shared information of real demand so that all the players in the chain are working with same demand and supply numbers. With this integration it is possible to achieve higher levels of on-the-self availability and lower inventories. Network based element can be described as a distinguishing feature of agile companies in their use of flexible arrangements with a wide supply base. The principle of agile network is to work with several suppliers instead of a small number of suppliers to achieve faster responsiveness. The agile supply chain demands also a high level of process alignment within the company and also externally with upstream and downstream partners. Due to process alignments it is possible to create "seamless" connections i.e. hand-offs or buffers that do not cause any delays between the different stages in the chain and transactions that are paperless (Christopher et al, 2004).

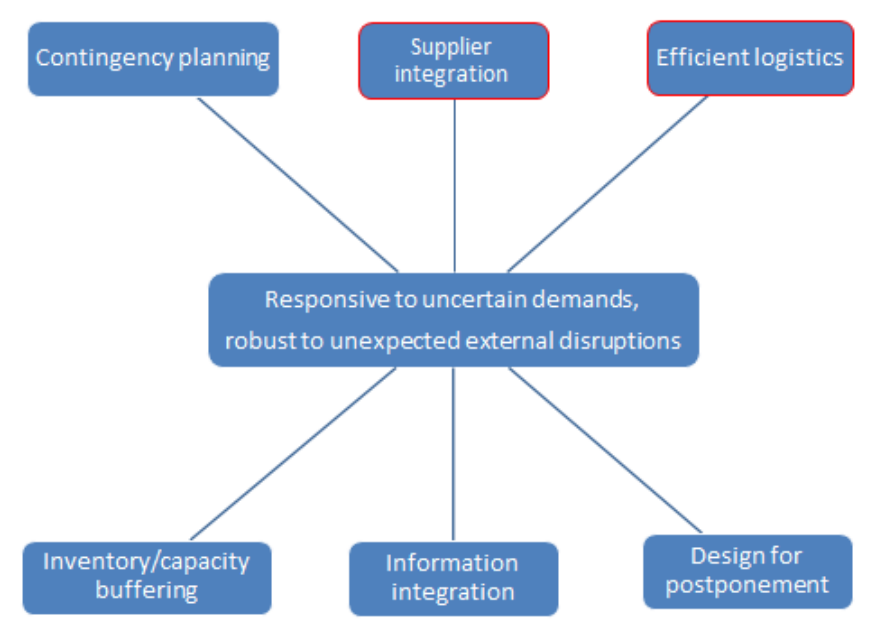

Figure 9: Foundations of agile supply chain (Lee, 2004).

According to Lee (2004), agile supply chain requires the elements presented in figure 9 . In this figure the link between design for postponement and agility illustrates how important it is to design the product in a way that enables a short pipeline. The right buffer 
inventory and appropriate capacity levels provide ways for the supply chain to prepare against unexpected developments. Efficient logistics refers to a cost-and time-optimized supply chain where short lead times play an important role. Information integration refers to information systems that should be harnessed to help supply chain members to establish partnerships for gaining better supply chain system performance. In other words an information system should give fast and accurate information about the demand and supply situation (Lee, 2004).

\subsubsection{Leagile Supply Chain Strategy}

Lean and agile strategy and optimal environment for them is illustrated earlier in this study. In case a company has a need for lean and agile supply chain solution, the right strategy is a hybrid model from above-mentioned solutions. This can be named "leagile" (Grant et al., 2006). According to Christopher and Towill (2001) hybrid models can be divided in to three different groups. The first model is based on temporary capacity which is purchased from outside to meet demand peaks while base demand is managed by lean principles. The second model can be described with $80 / 20$ phenomenon. Wherein $20 \%$ of the capacity uses lean principles, for example make-to-stock manner to fulfill the stable demand and rest of the capacity (80\%) is using agile principles such as configured-to order. The third model is based on postponement where semi-finished products are made by lean principles and the customization by agile principles (ibid). This strategy can be also described as mass customization.

The leagile solution can be illustrated through the de-coupling point. This solution requires the supply chain to be de-coupled to lean and agile parts. The decoupling point is a point in the chain where order-driven and forecast-driven activities meet. The objective of a leagile strategy should be to build an agile response on top of a lean basis by seeking follow lean practices up to the de-coupling point and agile principles after that point (Christopher, 2011). The concept is presented in more detailed level in chapter 2.4.2.

The case company's strategy can be best characterized as leagile, because the early phase of the supply chain is following leanness and cost efficiency principles, while closer to 
the end of the chain, the process requires agility to respond to the volatile demand of the customers. The focus of the study is to concentrate into the agile part of the supply chain. More of this will be discussed in chapter four.

The leagile strategy has many benefits compared to lean or agile strategies. Goldsby et al. (2006) point out that the leagile strategy holds less raw material inventory costs than the pure agile or lean strategies and this is directly proportional to the operational benefits. The authors also note that lean strategy results in excessive inventories as compared to agile and leagile strategies because it is based on forecasts. Especially if demand planning accuracy is about $60 \%$, then the leagile and agile strategies might be leaner than the lean strategy in practice. This indicates that the effect of long lead times does cause waste in the lean supply chain through the forecasting effect described in section 2.1.3. The lean model is also more vulnerable to demand and supply oscillations and that reflect in radical inefficiencies (ibid).

\subsection{Drivers for the right Supply chain}

\subsubsection{Availability drivers}

Availability is one of the most important factors what should be thought before choosing a right supply chain for a company. According to Corsten et al. (2004) significant cost penalty is incurred for manufacturers and retailers when stock-out occurs on the shelf of retailer. For example on a typical day a customer in the average supermarket will face stock-outs on 8 per cent of products. In figure 10 it is shown that how customers normally react when they face stock-out in the shop. From the figure it can be deduced that over 25 percent bought a different brand and 31 per cent said they would buy the product from somewhere else. This study represents clearly how poor the brand loyalty is in the markets and how stock-outs affect the manufacturer and the retailer. Also Bayle (2003) notes that over two-thirds of shopping decisions are made at the point of purchase, i.e. customers make the decision after they have seen the product on the shelf. In other words if the product is not on the shelf then there is a high risk that customer will not buy that product. 
In a worst case scenario, persistent stock-outs can also drive customers away from the brand. Thus, the potential loss of business caused by stock-out situations is obviously notable for both retailers and manufacturers.

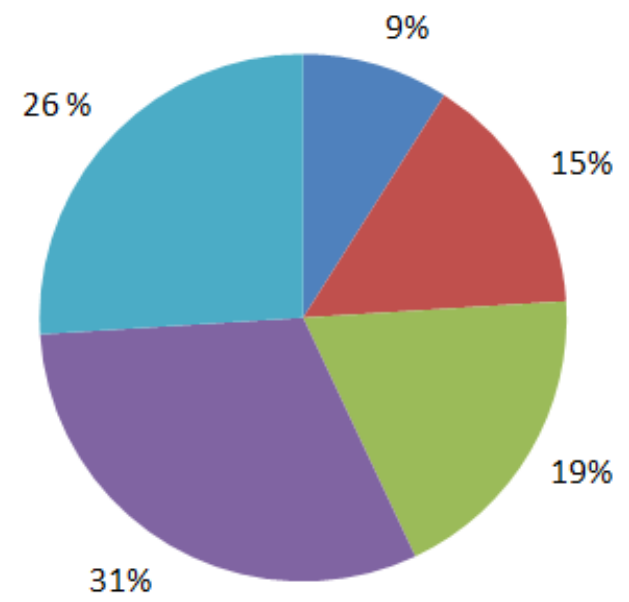

Do not purchase item

Delay purchase

- Substitute different brand

- Substitute same brand

- Buy item at another store

Figure 10: Customer behavior when faced with a stock-out (Christopher, 2011).

\subsubsection{Customer versus product point of view}

Shapiro (2001) notes that usually supply chain and demand management decisions are closely linked to firm's strategy and financial decisions. Supply chain decisions should be tailored together with company's strategy to succeed in competitive markets. For example Wal-Mart provides high availability of a diverse range of reasonably priced products at an affordable price. In a nutshell Wall-mart affords low prices and good product availability (Chopra and Meindl, 2010). McMaster-Carr sells maintenance, operations and repair items. It has more than 500000 different items in its selection of goods. Its competitive strategy is based on availability, convenience and responsiveness. Unlike Wall-Mart, McMaster-Carr does not compete with low prices but with responsiveness (ibid).

In the literature many different approaches are mentioned how to choose right supply chain strategy. From this thesis point of view the most suitable candidates are Fisher's 
theory (1997) where supply chain strategy is chosen based on products, whereas Collin et al (2009) has been fitted right supply chain based on customers demand chain.

According to Fisher (1997) right supply chain should be decided based on company's products. As it is earlier noted, he divides all products into functional or innovative category. Apportionment is based on products life cycle, nature of demand, product variety and et cetera (ibid). After a company has found out that is their product innovative or functional the supply chain strategy should be aligned with nature of the product.

Different products and customers need different kinds of Supply Chain Strategies. Products can be divided roughly in two different segments like Fisher has done (1997). First segment is for functional products which are identifiable from predictable demand and their product life cycle is longer than two years. The second segment has innovative products which are known from unpredictable demand and short product life cycles that are typically from 3 months to 1 year. Segmentation have been done on the bases of on demand predictability which gives recommendation whether Lean or Agile Supply Chain Strategy should be implemented. In table 1 main differences between functional and innovative products are presented.

Table 1: Functional Versus Innovative products. (Fisher, 1997).

\begin{tabular}{|c|c|c|}
\hline Segment & Functional & Innovative \\
\hline Nature of demand & Predictable & Unpredictable \\
\hline Product life cycle & More than 2 years & $3-12$ months \\
\hline Contribution margin & $5 \%$ to $20 \%$ & $20 \%$ to $60 \%$ \\
\hline Product variety & low & high \\
\hline $\begin{array}{c}\text { Average margin of error in } \\
\text { the forecast }\end{array}$ & $10 \%$ & $40 \%$ to $100 \%$ \\
\hline $\begin{array}{c}\text { Average stock out rate } \\
\text { Markdowns after EOL } \\
\text { phase }\end{array}$ & $1 \%$ to $2 \%$ & $10 \%$ to $40 \%$ \\
\hline $\begin{array}{c}\text { Lead time required for } \\
\text { make-to-order items }\end{array}$ & $6-12$ months & 1 day to 2 weeks \\
\hline
\end{tabular}


Collin et al. (2009) have divergent approach to supply chain strategy decision than Fisher. They argue that right supply chain strategy should be fitted to mate with the customer's demand chain. In their case study, the customers are allocated to three different segments which are illustrated in figure 11.
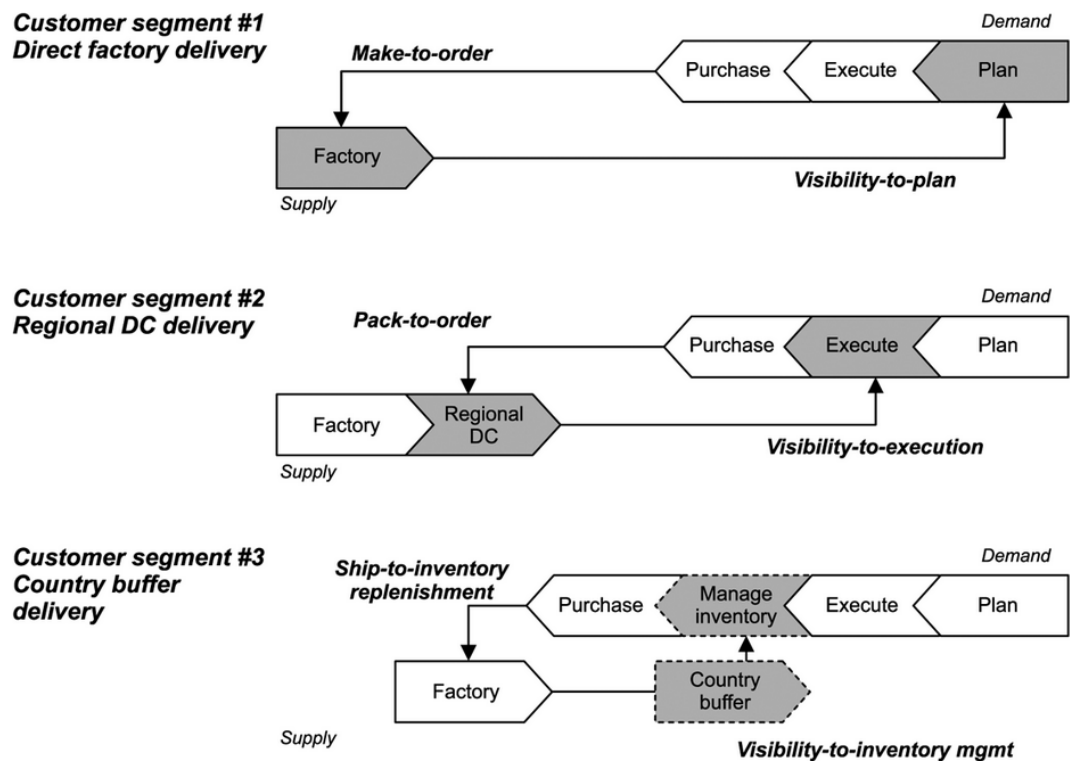

Figure 11: Three different demand chain segments (Collin et al., 2009).

In the case study, the first customer segment uses direct factory delivery as the customers have reliable plans and due to the accuracy plans the company can promise short lead times to the customers. A second customer segment employs regional DC deliver, which is a bit more responsive supply chain than the one mentioned earlier. This model is based on material buffers in regions on module level that gives flexibility to packing and shipping activities. Typical characteristics for a third customer segment are customer's poor demand visibility and inaccurate planning and execution that cause challenges to the service provider. These challenges can be minimized by a country buffer-based supply chain and vendor-management inventory as is presented in figure 11 (Collin et al., 2009).

\subsubsection{Cost drivers}

In the field of fast moving consumer goods (FMCG) it is important to use supply chain strategy when there is investment in quality, service level and lead-time as those are 
market winners in volatile business environment (Christopher and Towil, 2000). Also Fisher (1997) states that where the risk of obsolescence and/or the cost of stock out is high relative to the cost of production and distribution, then a different supply chain solution is required than Lean Supply Chain. By using above -mentioned factors a formula can be made which leads to the conclusion that total costs for the Product Delivery Process (PDP) are:

Supply Chain Total PDP Costs $=$ Physical PDP Costs + Marketability Costs

Where, Physical Costs includes all distribution, production and storage costs. Marketability Costs includes all obsolescence and stock out costs (Christopher and Towill, 2001).

According to Christopher (1993) and Grand et al. (2006) the target of the company should be to reduce the total cost of logistics activities and not to focus on each activity in isolation. Reducing costs in one part of the chain, such as inventory carrying, might increase transportation costs as faster deliveries is needed to keep inventory in optimal level. Grant et al. (2006) argue that major cost categories of logistics should be divided into six groups. These categories are illustrated in figure 12.

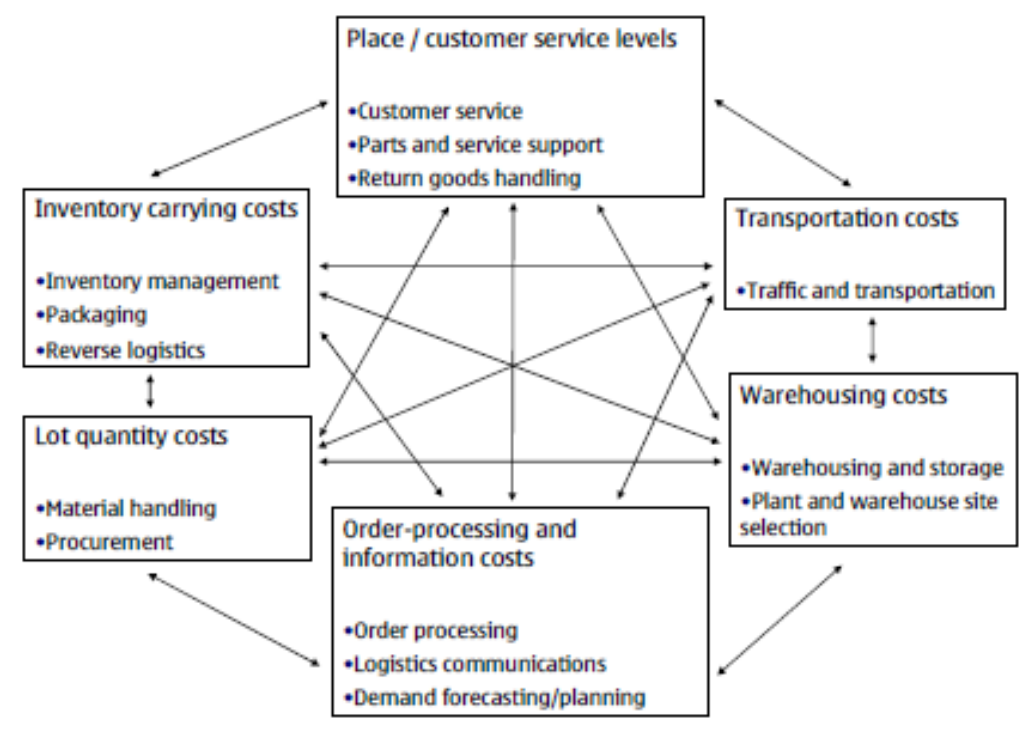

Figure 12: How logistics activities drive total logistics costs (Grant et al., 2006). 
Grant et al. (2006) note that the key cost trade-off associated with varying levels of customer service is the cost of lost sales. The money that are spent to increase customer service level include parts, order fulfillment, service support and returned goods handling which has the major impact to customer satisfaction. This customer satisfaction has also significant influence to future sales due to word-of-mouth negative publicity from former customers. Transportation costs can be divided by customer, inbound, outbound and product line and et cetera. Costs vary a lot and depend on weight of shipment, volume of shipment, chosen mode and point of origin and destination. Warehousing costs include all costs from warehousing and storage activities. Costs vary due to a change in the number or location of warehouses. Order-processing and information system costs refer to order processing, distribution communications and demand forecasting. Lot quantity costs come from purchasing or production activities and vary a lot based on order size and frequency, setup costs, capacity lost due to downtime during changeover of line, materials handling and price differentials. Inventory carrying costs can be divided to four categories: cost of capital, inventory service cost, storage space cost and inventory risk cost (Grant et al., 2006).

Fisher (1997) has a different kind of approach to supply chain total costs. He notes that supply chains have two separate functions and related costs. Physical costs are defined as costs of production, inventory and transportation whereas market mediation costs are a result of a situation where supply exceeds demand. This can cause markdowns and a situation where the product must be sold at a discount or even at a loss. This holds good also the other way round i.e. in the case that demand exceeds supply a company faces shortage and lost sales opportunities which dilute customer satisfaction (Fisher, 1997).

Also Shapiro (2001) has his own categorization model of total supply chain costs. His model is similar to previous mentioned examples and it is based on the idea that different activities drive costs along the logistics pipeline. He divides costs to eight different groups, which are presented below:

- Raw material and other acquisition costs

- Inbound transportation costs 
- Facility investment costs

- Direct and indirect manufacturing costs

- Direct and indirect distribution center costs

- Inventory-holding costs

- Interfacility transportation costs

- Outbound transportation costs

FMCG industry is also known from its attribute that lost sales are gone forever whether the cause is due to stock outs or due to obsolescence. This is because it is an extremely rude and competitive marketplace with little brand loyalty i.e. customers demand that products should be inexpensive and available in the same time. These requirements set challenges for supply chain because to guarantee good availability shops should keep inventories, which create costs and that reflects directly to the end price of the product.

\subsection{The role of visibility in supply chain optimization}

In this subchapter a few different theories which can be used to increase visibility in the supply chain are presented. These theories are chosen to support the research hypotheses and empirical part of the thesis that are strongly linked to end-to-end visibility. Theories handle mainly demand visibility in the supply chain which can be linked later to benefits of activation data from devices.

\subsubsection{Demand Visibility Point and Order Penetration Point in supply chain optimization}

The interaction between demand and supply are described using the demand visibility point and order penetration point constructs. The demand visibility point is defined as the point in the demand chain where the customer selects the supplier, and from which point on the customer can provide the supplier with visibility of demand. The order penetration point is the mirror image of the demand visibility point. It is defined as the point in the supply chain where the supplier allocates the resources to fulfill the customers demand 
(Holström et al., 2009). Demand visibility point is much more important for this thesis than order penetration point as empirical part of the thesis concentrates to proof how inventory levels has been changed due to improved demand visibility.

In the case company demand visibility point has been moved a while ago from sell-in to sell-out due to activation data utilization. With this change is possible to decrease bullwhip effect in the supply chain because actual demand is visible and not only sell-in. With this change is possible to decrease bullwhip effect but not to remove the whole effect as there is still existing batch ordering and all of customer stocks are not visible for the case company.

\subsubsection{The decoupling point}

As earlier is noted that the case company's supply chain must be lean to keep costs low and in the same time agile to response fluctuating demand. Lean and agile supply chain can be achieved through the creation of a decoupling point. There the idea is to hold strategic inventory in some generic or modular form and only complete the final assembly/configuration when the actual customer requirements are known (Christopher \& Towill, 2001). According to Hoekstra et al. (1992) the decoupling point can be explained through an important stock point - from which the customer has to be supplied. The decoupling point can be seen also in the case company where supply is forecasted and execution is done based on activation data from devices. In other words case company utilizes lean principles up to the decoupling point and agile methods beyond it. The foregoing is summarized in figure 13. 


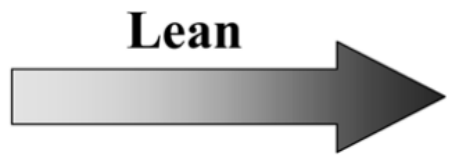

- Forecast at generic level

- Economic batch quantities

- Maximise efficiencies
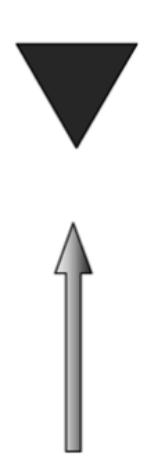

Strategic

Inventory

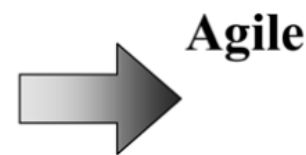

- Demand driven

- Localised

Configuration

- Maximise effectiveness

Figure 13: The decoupling point (Christopher \& Towill, 2001).

\subsubsection{The benefits of visibility}

In the literature are several different researches that support a theory of increased demand visibility reflects direct to inventories or availability. According to Christopher et al. (2004) it is possible to achieve higher availability and lower inventories due to increased information in the supply chain. In other words if all players in the supply chain are working with same demand and supply numbers this should turn up in lower stocks and improved availability. Lack of visibility can be also linked to bullwhip effect that have to be minimized for example shorter lead times i.e. shorter lead times usually creates extra costs for a company. Other option is to make more accurate forecasts but it is much easier said than implemented in practice. So in practice by improving visibility a company can reduce bullwhip effect and move from forecast driven supply chain to demand driven supply chain. Even increased visibility decrease bullwhip effect it still occurs always because batch ordering and uncertain demand can't be removed from the supply chain.

\subsection{Summary of the literature review}

In the literature part of this thesis was used to extensively to analyze different factors of supply chain management i.e. three differing strategies, demand visibility in the supply chain, the role of lead-time in supply chain management and drivers in choosing the right 
supply chain. The analysis is made from an end-to-end perspective to support the empirical part of the thesis. As the empirical part is very unique and previous literature of activation data utilization was not available, the literature review is linked to the empirical section mainly through different supply chain strategies, demand visibility and information increase as those are gained benefits from activation data. Other topics help reader to understand what supply chain management is and how different variables influence to it.

According to literature review a conclusion can be made that long lead time increases forecasting error and bullwhip effect, which increases need for safety stocks and more inventory to be held on average to guarantee availability. Inventory holding costs are one of the key drivers when company is choosing the right supply chain for their business. Especially for the case company inventory holding costs causes a lot of challenges because technology becomes obsolete very quickly and volumes are huge in the supply chain. As earlier in this thesis is noted these are characteristics of the business environment which can't remove but can be minimized with different methods.

The case company's cost efficiency solution for minimizing this uncertainty is a new control point in the supply chain which steers it based on real demand of devices. With this new type of solution is possible to increase demand visibility in the supply chain i.e. increase information in the supply chain to achieve higher availability and lower inventories. In the past uncertainty has to be minimized by investing much more money and resources to accurate forecast processes or shorter lead-times. The solution will be tested further in this thesis in the empirical study but according to the literature review it should work in uncertain environments and with all products where activation data is available and its coverage is big enough. 


\section{RESEARCH DESIGN}

In this chapter the research approach of this study is first introduced. Then, it continues to discuss methodological choices: selection criteria for the case products, methods for data collection as well as methods for data analysis.

\subsection{Case study as a research method}

Case study is a research method which focuses on understanding the dynamics present within single settings. Case studies usually include data collection methods such as relevant literature, interviews, questionnaires and observations. The observations include qualitative part (words), quantitative part (numbers) or both. Further, case studies can be used for the following purposes: to provide description, generate theory or test theory. As the process under examination is a unique and present phenomenon situated in a real-life context, case study is a suitable research method (Eisenhardt, 1989).

\subsection{Case selection}

In this thesis, a case study refers to a supply chain optimization and inventory management with real time demand data. The object of the study is to discover how real-time activation data and channel information can be used to improve sell-in and sell-out optimization. In chapter 4 , this is explained in a more thorough manner.

The topic of the study was selected in order to get a broad view of the benefits of realtime activation data and to explore new ways to optimize case company's supply chain in Europe region. The scope of the case was outlined based on professor's and instructor's guidance. By selecting at least two products into the scope implications can be made about how research hypothesis works in practice.

These two products were selected in order to get a broad view to the case company's supply chain in Europe level and these compose most of the Europe sales in volume. In 
other words, if the research hypothesis works with these two products it should also work with rest of the products where activation data coverage is more than $90 \%$.

\subsubsection{Product A - Low-priced smartphone}

This product belongs to the low price point of company's smart device portfolio. There was no product transition ongoing which means that this was the first product launched in this price point. In the sales start was not high expectations regarding sales but demand exceeded continuously the planned volumes and production capacity from the beginning to the end of the life cycle. The execution succeeded and no major material constraint was noticed.

\subsubsection{Product B - Mid-priced smartphone}

Second product belongs to the mid-price point of company's smart device portfolio. It can be called as upgraded version of the case product A due to bigger screen and better camera. The product was introduced in July 2013 and some weeks after sales started, demand was much lower than expected. During the research horizon demand and supply were balanced and thus availability was always in good level.

\subsection{Data collection and methods for analysis}

In this research, the case study was done by first collecting channel inventory data and occasional discussions with persons that were involved in the use of activation data or its development. Most of the discussions were done with colleagues who were already familiar to me and supply chain details in general level was known so there was not a need to make wide interviews for people. Based on this information, descriptions of the case study were written and conclusions were drawn. Along the research process, collected data was re-analyzed in order to reshape the case descriptions to answer better to the thesis' research question. All in all, the whole topic is quite new in the case company and people are continuously developing ways to utilize it better. 


\section{CASE REAl time ACTivation data}

The case company has recognized the need to optimize its supply chain with real time demand data. At the moment the company has tools to optimize its supply chain with several different global parameters but experiments from real time activation data driven supply chain optimization are still exiguous. Nevertheless, it has been acknowledged that there is a link between inventory levels and amount of information in the supply chain. By increasing relevant information in the supply chain it is possible to decrease inventory levels without causing stock-outs for customers.

This thesis supports the case company by providing 1) understanding of the impact of real time activation data and channel inventory information in supply chain management and 2) a way to approach the cost impact of high channel inventory levels and poor availability. The goal of the empirical part is to illustrate how inventory levels can be brought down by changing the control point of supply chain and still avoid stock-outs.

The case company is one of the leading consumer electronics and software manufacturers which supply chain strategy based on agility and leanness. Variable value offerings and customer requirements in terms of availability and service level cause challenges for the use of one supply chain strategy. As it was earlier stated in the literature review, "one size does not fit all" and this is also taken into account in the case company's supply chain designing. However, optimizing the supply chains for all the different products in the portfolio is very challenging from total cost point of view.

The case company's products can be divided roughly into two categories, "innovative" and "functional" products. These two categories use different business models in terms of supply chain management. The business environments for these two categories differ from market requirements point of view i.e. for example market areas, value offering and product features are different. With this split it is easier to utilize appropriate supply chain strategy for all products. The scope of this case study is innovative products and their supply chain in Europe level. As the real time activation data is the most accurate for the innovative products, the scope is chosen to include only them. Innovative products have 
also more uncertain demand compared to functional category as Fisher (1997) has noted in his studies. Decreasing prices in the telecommunication industry is a common trend as product life cycles are short and this is emphasized on innovative product category. Due to these realities channel management is a special focus area to minimize marginal erosion during the product life cycle. Product and strategy apportionment is summarized in table 2 and more about the supply chain strategies will be discussed further in next section.

Table 2: Case company's supply chain strategies for different products.

\begin{tabular}{|c|c|}
\hline Product & Supply chain strategy \\
\hline Functional & Lean supply chain \\
\hline Innovative & Leagile supply chain \\
\hline
\end{tabular}

General characteristics of the business environment can be dived into five key characters, which are high volumes, uncertain demand, short lifecycles, a wide variety of products and price erosion. These characteristics are explained below:

1) High volumes are required and they make it possible to be cost efficient due to scale of economics.

2) Uncertain demand together with low forecast accuracy create unpredictability, which can be seen as a bullwhip effect in the supply chain.

3) Short lifecycles cause challenges to managing the ramp-up and ramp-down efficiently and effectively from total cost point of view i.e. market timing is crucial to maximize profit over product lifecycle.

4) A wide variety of products and different colors impact direct to planning accuracy and the response time of the supply chain. A flexible supply chain is a must to ensure good availability.

5) Price erosion is very fast in case company's business environment so availability plays an important role in the critical lifecycle phases.

In the case company's market can be seen some general characteristics. In Europe region main focus is set to innovative products as they have higher profit potential than functional 
products. Major challenge for these products is demand forecasting due to volatile demand and high volumes. High gross margins are typical for innovative products and therefore product availability is a key factor for maximizing profit. Normally innovative products are over planned because of the cost of losing a deal is higher than cost of unused capacity. In other words maximizing availability is extremely important for supply chain management.

Case company's product portfolio is very wide and most of the products are available in several colors and variants, which cause different kind of challenges in supply chain management. The importance of an agile and lean supply chain will grow along the variety of the offering and special attention should be given to supply chain optimization decisions.

Short product lifecycles are typical to the telecommunication industry. Hence the product portfolio is constantly updated with new products, which reflects directly to the price erosion. Products can be updated with new features and by providing new value offerings to customers it is possible to extend product lifecycles. Thus, the character of the product and its lifecycle steer supply chain management decisions. Above mentioned characteristics and implications are summarized in table 3.

Table 3: Characteristics of business environment and their implications.

\begin{tabular}{|c|c|}
\hline Characteristics & Implications \\
\hline Price erosion & Availability is key to success \\
\hline Short product lifecycles & Special focus on ramp-up and ramp-down \\
\hline Volatile demand & Flexibility is mandatory \\
\hline Wide product offering & Variant management \\
\hline High volumes & Cost minimization \\
\hline
\end{tabular}




\subsection{Current supply chain strategy}

The case company is one of the leading consumers electronic and software manufacturer which supply chain strategy based on agility and leanness. Variable value offerings and customer requirements in terms of availability and service level cause challenges for the use of one supply chain strategy. As was earlier noted in the literature review "one size does not fit all" and this is also taken into account in case company's supply chain designing. However, optimizing the supply chains for all the different products of the portfolio is very challenging from total cost point of view.

The case company's products can be divided roughly into two categories, "innovative and "functional" products. These two categories use different business models in terms of supply chain management. The business environments for these two categories differ from market requirements point of view as well i.e. for example market areas, value offering and product features are different. With this split is easier to utilize appropriate supply chain strategy for all products. The scope of this case study is innovative products and their supply chain in Europe level. As the real time activation data is the most accurate to the innovative products, the scope is chosen to include only them. Innovative products have also more uncertain demand compared to functional category as Fisher (1997) has noted in his studies. Decreasing prices in the telecommunication industry is a common trend as product life cycles are short and this is emphasized on innovative product category. Due to these realities channel management is a special focus area to minimize marginal erosion during the product life cycle. Product and strategy apportionment is summarized in table $\mathrm{x}$ and more about the supply chain strategies will be discussed further in next section.

\subsection{Supply chain setup at case company}

In chapter 2.2 are illustrated three different supply chain strategies and the case company's supply chain strategy in Europe region is discussed here. In general level the case company can be described as a lean manufacturer of consumer electronics. However, the case 
company's supply chain strategy has adopted lately "leagile" characteristics, which can be seen in a huge development step for a long time. Before supply chain steering was based on forecasts and order intakes, whereas currently only capacity is planned and execution is done based on activation and channel inventory data. With this change is possible to achieve more stable inventory levels and less stock-outs and over stocks. New steering principles are illustrated in figure 14.

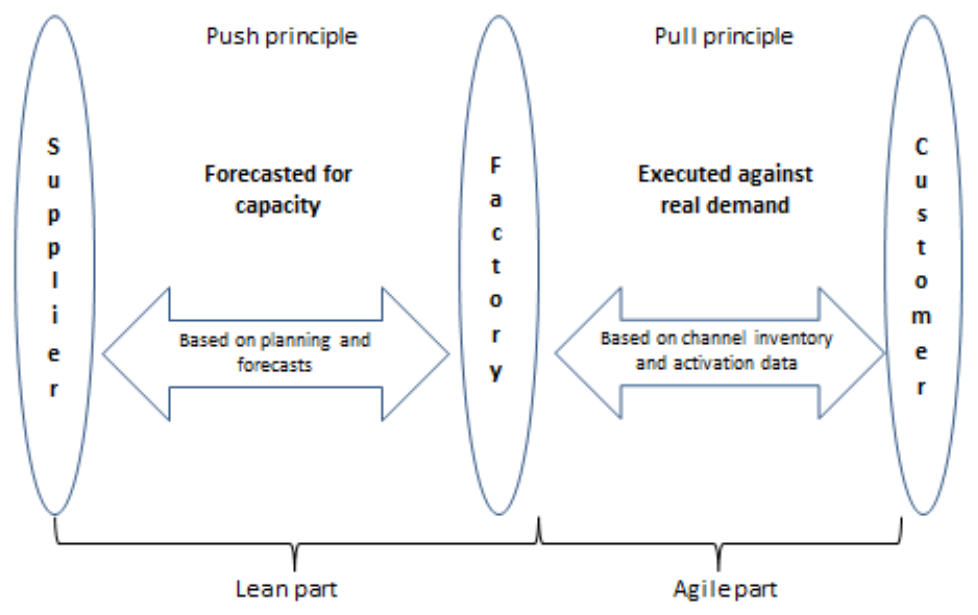

Figure 14: The case company's new supply chain strategy.

The purpose of the change is to get advantages from both strategies. From lean strategy is adopted stable production capacity, low inventory levels and cost effectiveness while responsiveness and agility is adopted from agile strategy. The company has combined these two different elements successfully without losing their responsiveness or cost efficiency. Because of the company's business environment these development steps are vital in competing markets where service level, costs and availability define market winners. The case company has a wide product portfolio for which demand scenarios varies a lot across products and geographical markets. The agile part of the supply chain is an answer to better availability without losing cost efficiency as uncertainty and low forecasting accuracy is impossible to remove from the business environment. 
The case company has assumed that by using channel inventory information and real time activation data it is possible to improve customer service level and reduce noise from the countries due to better availability. Even though the company has noticed that real time activation data can be used to increase availability, they do not have any statistical proof for that. The goal of this thesis is to illustrate and examine how use of real time activation data has been impacting inventory levels and case company's supply chain management in Europe.

\subsection{Supply chain setup for sell-in management}

In the case company a new sell-in management process has been implemented which allows supply chain to be more agile than earlier. This new process takes advantages of real time demand data that is based on activation information of products. Every time when consumer buys a new phone and activate it, the case company receive an information where one can find for example product name and shipping information. The data is used for managing sell-in properly to avoid overstocks and understocks in Europe. The data can be used for supply chain steering almost during the whole product life cycle except in the channel fulfilling phase when activation data is not available. Activation data can be called as a real-time activation data, but there is still a short delay from the moment of purchase to activation of device. For example after Christmas usually a huge activation peak can be seen because most of the devices have been bought as a gift. 


\section{RESEARCH FINDINGS}

In the previous chapter, the case company's business environment, supply chain strategy and supply chain setup were described in detail in order to recognize the effect of changes in the supply chain. The chapter at hand discusses the research findings from the empirical study and presents a synthesizing analysis of the results with respect to the thesis' research question and overall purpose.

The scope was outlined for product A and B because they represent the majority of innovative products volumes. The investigated time frame is divided into two sections, first section include period of time where activation data was not utilized and other section include period of time where activation data was utilized in Europe and area level but not in customer level. Customer level inventory optimization was done by sales areas or focus countries without activation information. These time frame definitions are based on instructor's guidance as he was involved in supply chain optimization of both products.

The purpose of this chapter is to investigate earlier mentioned hypothesis of lower inventory levels without facing stock-outs or overstocks. The validation has been done for two different products by comparing DOS levels and healthy inventory levels in two different time frames. The analysis includes Europe, country and customer level inventory information where it can be seen how new process has affected the inventory levels. Limiting values for DOS and healthy inventory level are defined together with thesis instructor and are based on supply chain channel structure of product.

\subsection{Product A}

In figure 15 it is presented how inventory level has been developed against activations in Europe level. Figure has been divided into three sections to better illustrate how inventory behaves in different time frames. By excluding launch phase from DOS level comparison, it is possible to compare sell-in and forecast driven supply chain (old way) to activation data driven supply chain. 


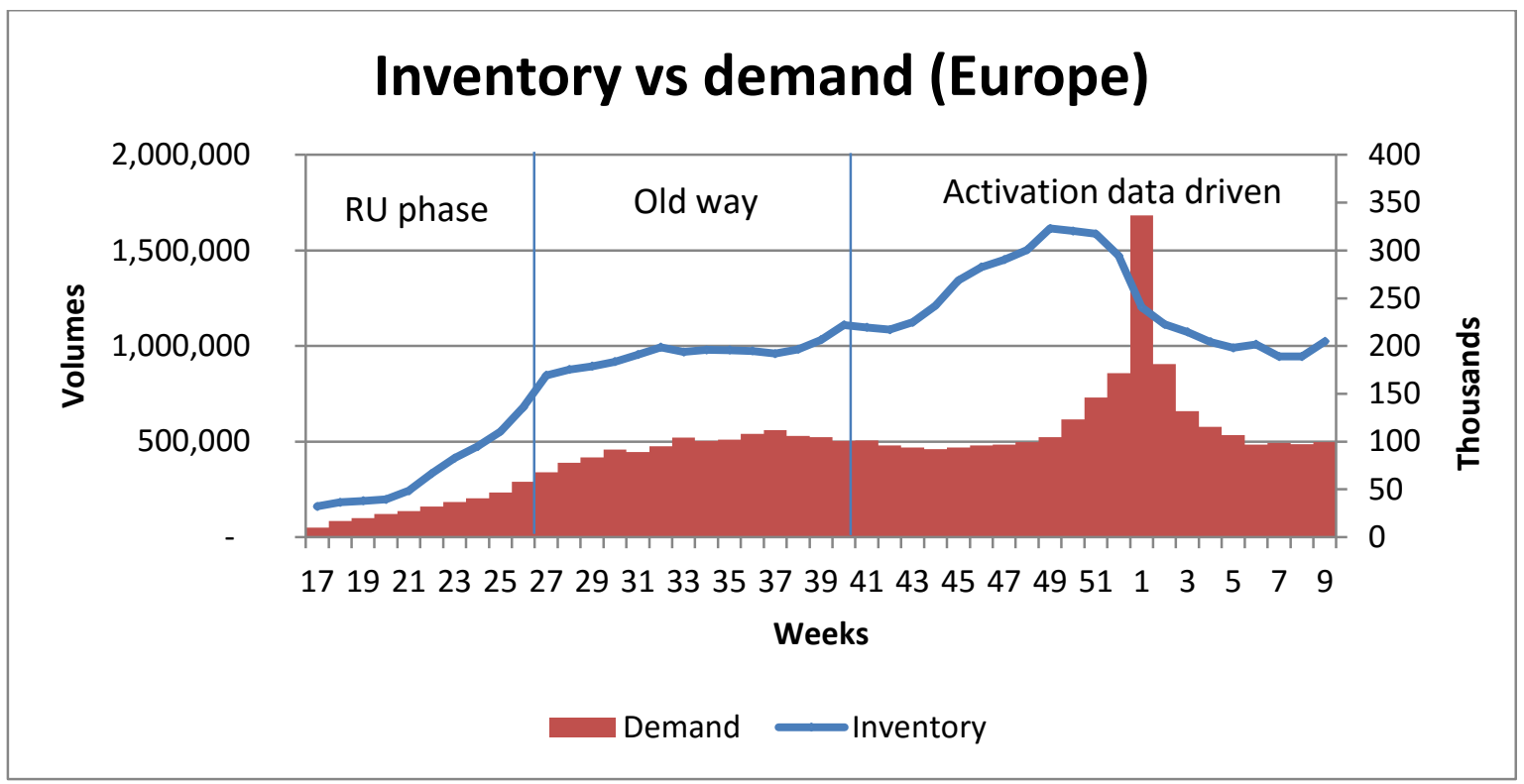

Figure 15: Historical inventory vs demand data for product $A$ in Europe.

In figure 15 can be seen clearly how seasonality affects inventory levels even when activation data is used for inventory optimization. With this so called channel fill maximal availability can be ensured in Christmas sales which is one of the most crucial times for electronic industry in profit point of view. After RU phase, it can be seen how demand has stabilized to 100000 activations/ week but still inventory level fluctuates a bit. A strong peak in the beginning of the year is due to short delay of activation, because many devices have been bought as a gift and they are activated after Christmas. Other thing is that activation data is updated once a week in the system so there is always one week delay in the data. Also current activation coverage causes a tiny error to activation figures as it is scaled up because coverage is not fully $100 \%$.

In figure 16 DOS level from the whole product life cycle of product A is presented. DOS fluctuates quite much in every time frame but with linear line it can be seen how DOS has a decreasing trend which indicates that the hypothesis might be valid for product A. From the figure can also be seen a typical channel fill from week 37 to week 49 and a huge DOS crash after the Christmas sales due to activation delay. DOS went all the way down to 42 days and with activation data driven execution DOS was stabilized to 70 days which is 
quite near to target level of product A. In other words, without real-time activation data inventory runs the risk of being impacted by the bullwhip.

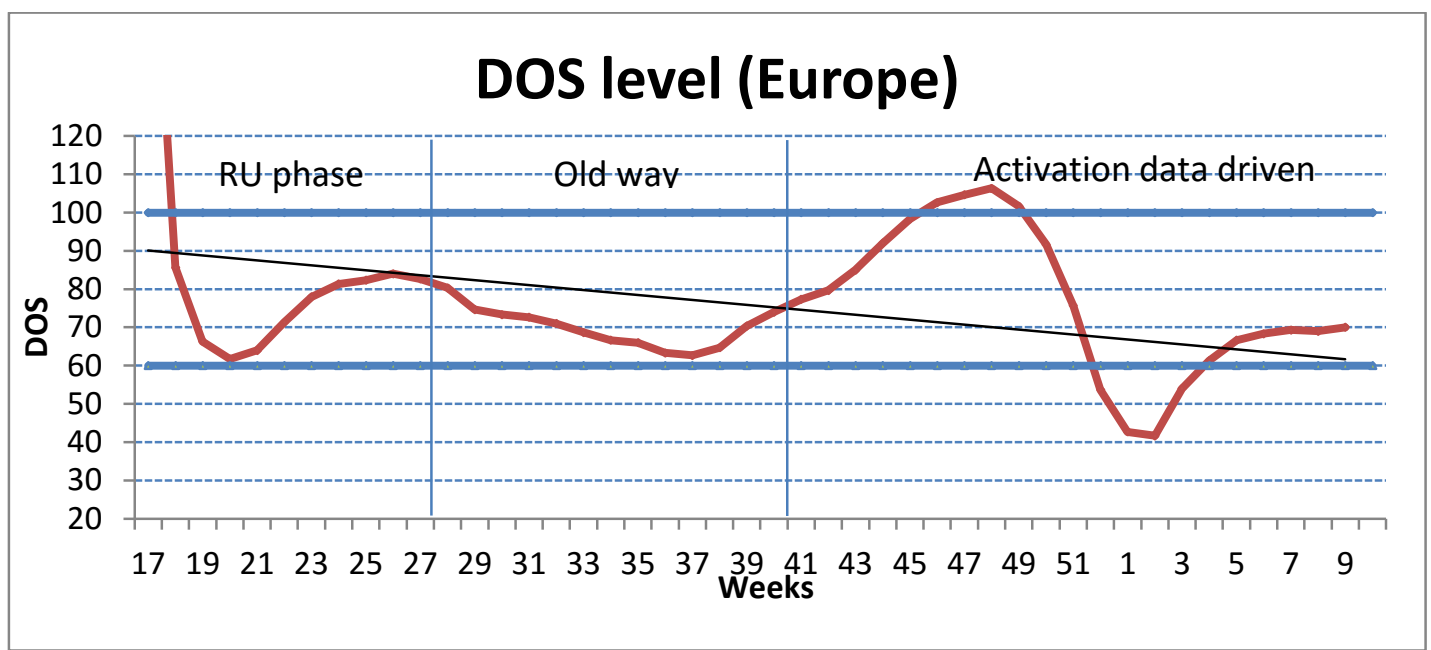

Figure 16: Historical days-of-supply data for product $A$ in Europe.

Healthy inventory level is defined the following way for product A in the case company. In case DOS is under 60 days or over 100 days, then it can be said that inventory is unhealthy, but if DOS is something between 60 and 100 days the inventory is described as healthy inventory. In perfect situation DOS should be 80 days as it is defined as a target level.

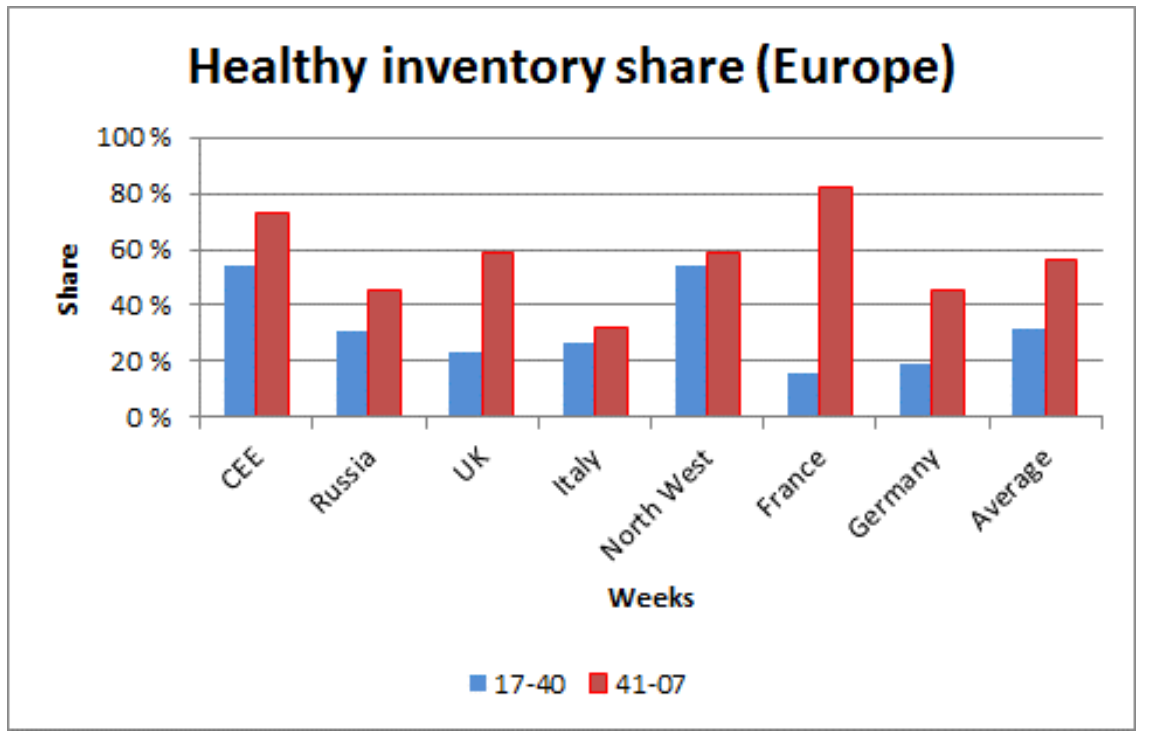

Figure 17: Healthy inventory share for product $A$ in different European markets. 
Different markets are presented on $\mathrm{X}$-axis and on $\mathrm{Y}$-axis is illustrated how many percent of time inventory has been in healthy level. From the figure it can be seen that average healthy inventory share is increased from $32 \%$ to $56 \%$ i.e. healthy share has been improved by $57 \%$. In the case that measure of healthy inventory would be presented by volume instead of time, result will be much bigger, because shipped volumes are higher in the end of the year than in summer due to seasonal demand.

Below is presented how the DOS level has changed after demand activation data utilization. RU phase is removed from comparison and DOS is a weighted average by shipped volumes. It can be seen that inventory levels has been decreased from 109 days to 80 days, which is actually the E2E DOS target in Europe. In other words, inventory levels have been optimized to the right level due to activation data driven execution.

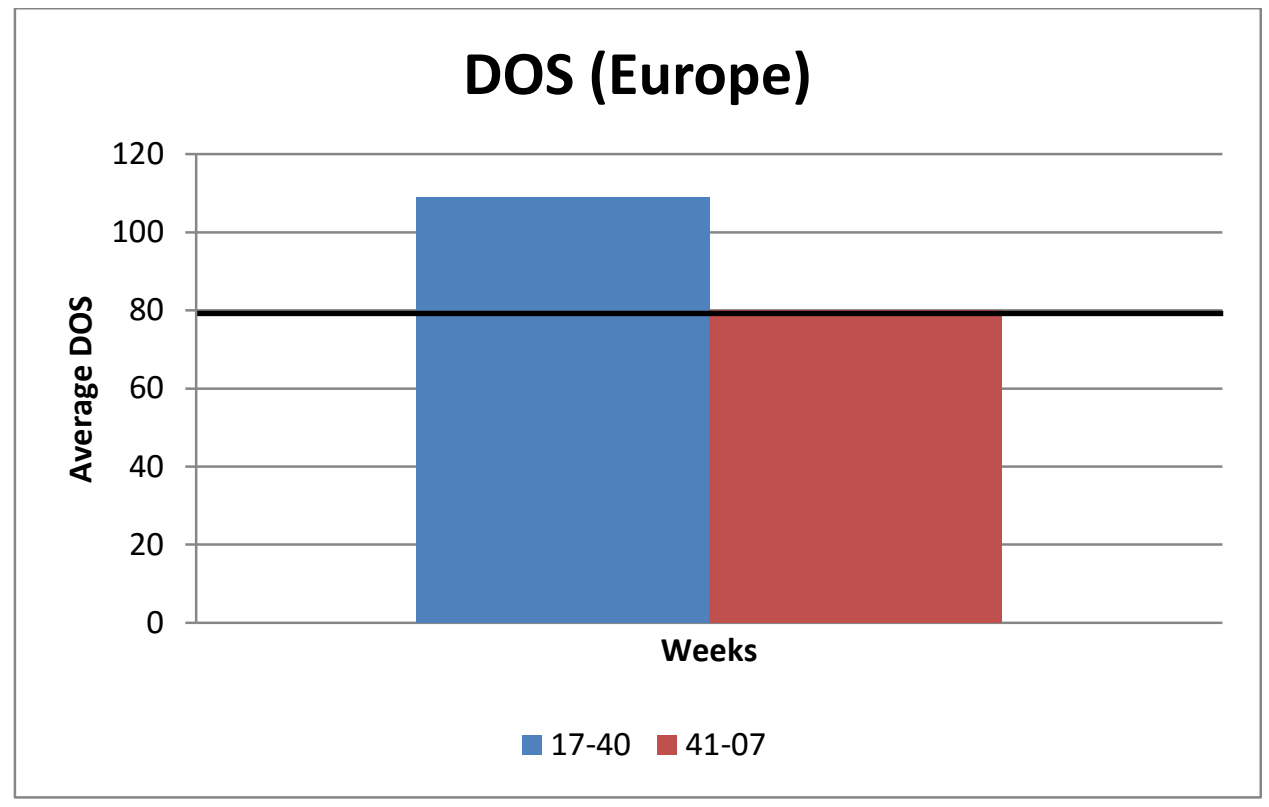

Figure 18: Weighted average DOS comparison in European markets.

In figure $\mathrm{x}$ is presented the inventory status for product $\mathrm{A}$ in Europe. Figure consists of three different variables that show how big part of inventory is healthy level, overstock or understock. The ideal situation is when whole figure is in blue but actually in real life it is practically impossible to execute because in RU phase and before Christmas the channel will be filled to maximize availability. Also in the beginning of January there is a huge 
activation peak which can be seen from figure $\mathrm{x}$. Following mentioned characteristics can be seen from below figure. This data indicates similar things than the first chart of this chapter i.e. the bullwhip effect is higher in "old way" than in activation driven phase if channel fills and the activation peak are excluded from inspections of data.

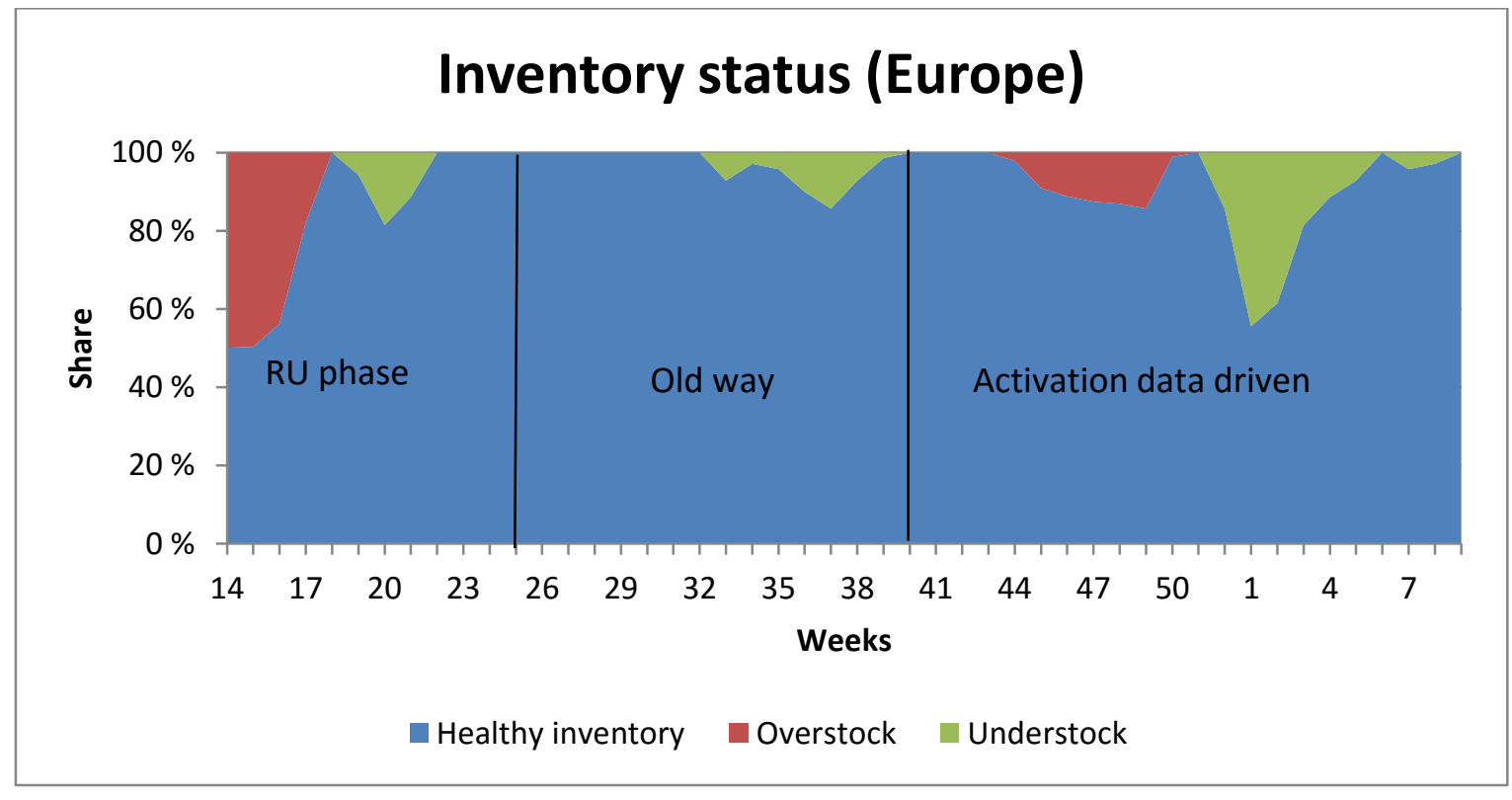

Figure 19: Inventory status for product $A$ in Europe.

In some countries there can be seen same kind of behavior as in Europe. In RU phase there is a huge increase of inventory levels because forecast drives supply not the actual demand. Also in figure 20 it is possible to see how inventory levels fluctuate quite much even when demand is stabilized in around 20000 activations/week. Activation data driven part shows how demand and inventory have been developing the same way. Only exception is this huge activation peak in week 1 due to Christmas sales which is taken into account during execution. 


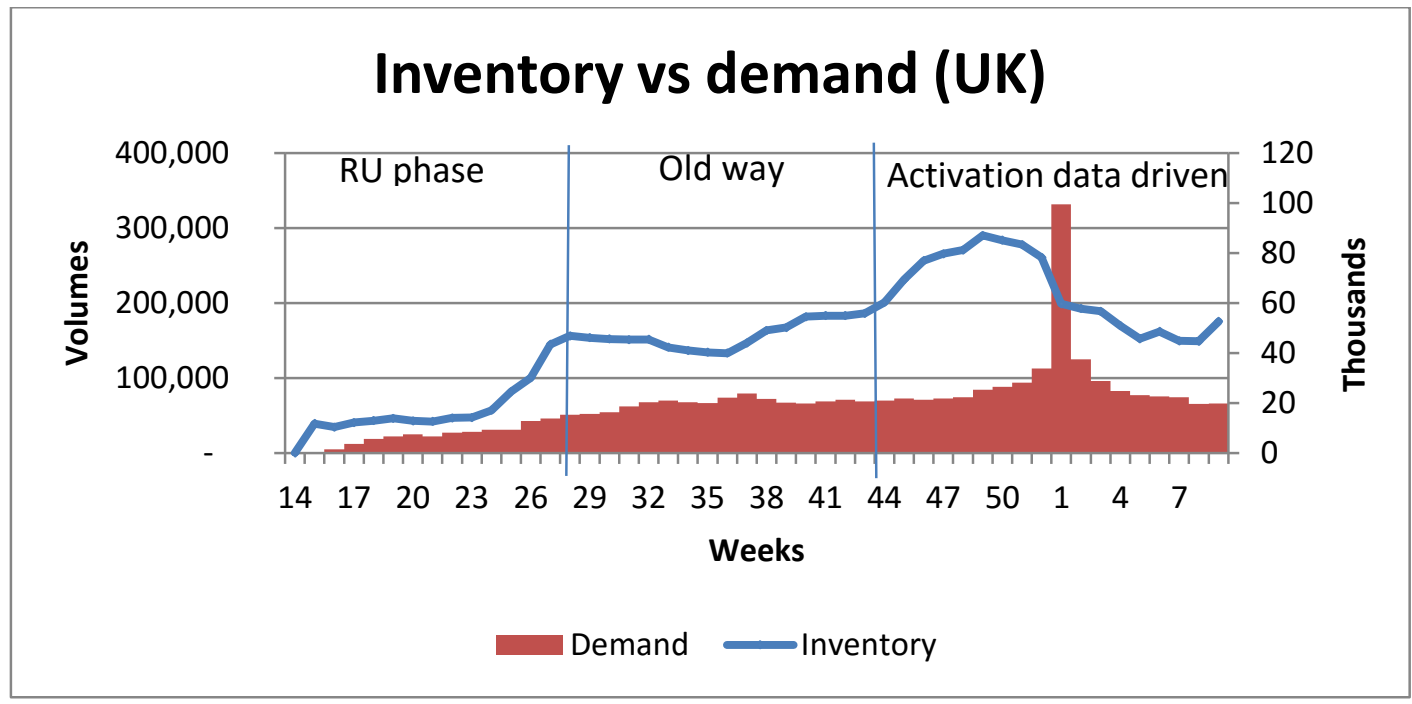

Figure 20: Historical inventory data for product $A$ in UK.

In France one can't see big differences between old way and activation data driven supply chain. Actually demand and inventory level is in good balance from week 20 to week 9 . These two parameters behave almost identically during the whole time frame i.e. when demand increases also inventory volume increases and vice versa. Only one exception time frame occurs from week 3 to week 6 where inventory volume increases and demand decreases. Probably the reason for this is over planned supply because huge activation peak in the beginning of the year causes challenges for demand planning.

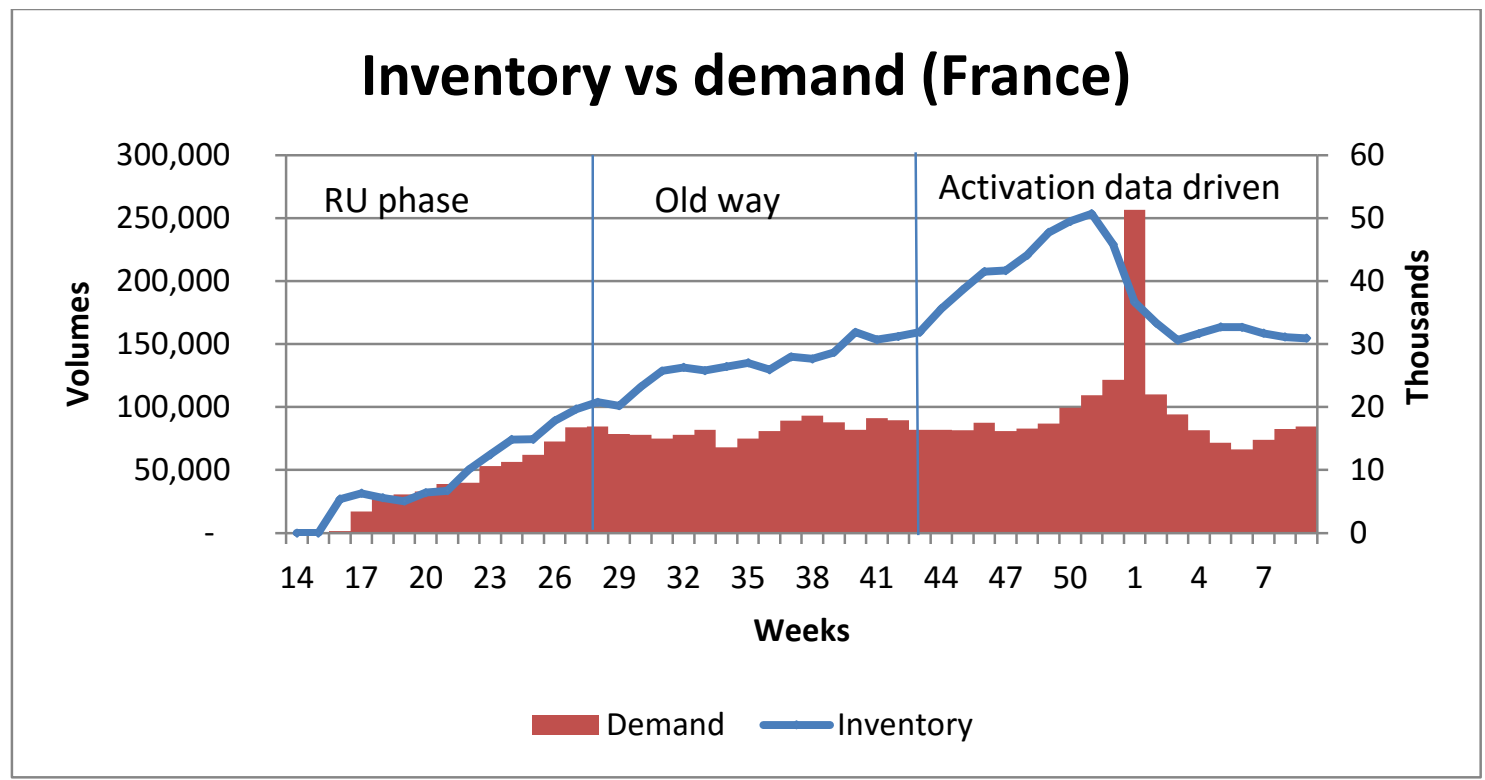


Figure 21: Historical inventory data for product $A$ in France.

From figure 22 can be seen very quickly how activation data driven supply chain has affected healthy inventory share in UK and France. Non weighted average shows that healthy inventory level has been increased over $200 \%$ due to a new supply chain control point and better demand visibility. This figure supports very well an assumption that healthy inventory share can be increased with changing control point in the supply chain.

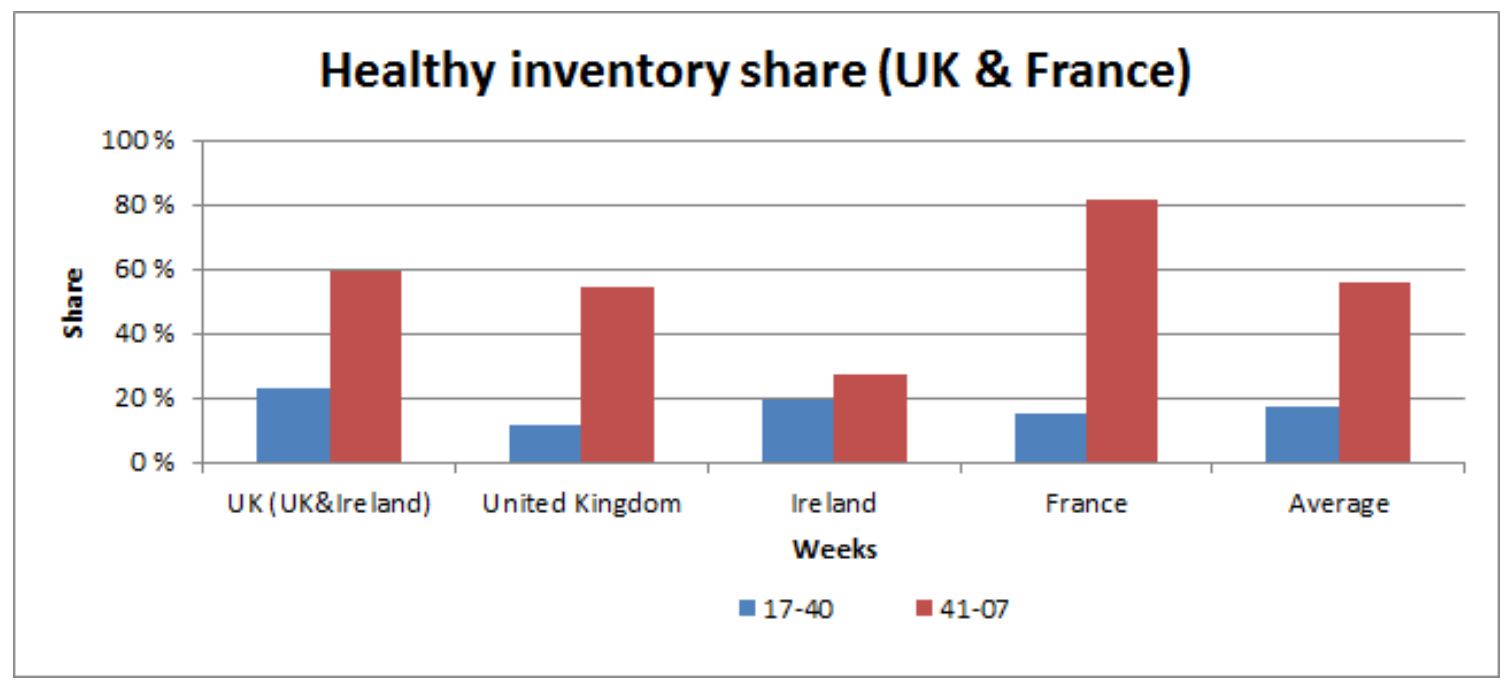

Figure 22: Healthy inventory share comparison for product A.

Just observing average measure does not tell absolute truth about gained benefits because it is not weighted with volumes. For example France and UK sell a lot more than Ireland and due to this fact weighted average should be bigger.

In figure 23 is illustrated how activation data driven execution has affected inventory levels compared to forecast and order intake driven execution in country level. In the study a weighted average DOS data is used to minimize error due to seasonality and activation data delay. For example in France DOS has been 59 days in week 17-40 and with steering supply from other countries to markets where real need is, DOS has moved closer to the DOS target without causing demand fluctuations to the factory or inflicting stock out risk to other countries. By comparing DOS levels between UK and France it can be seen clearly what the benefits of new supply chain control point are. 

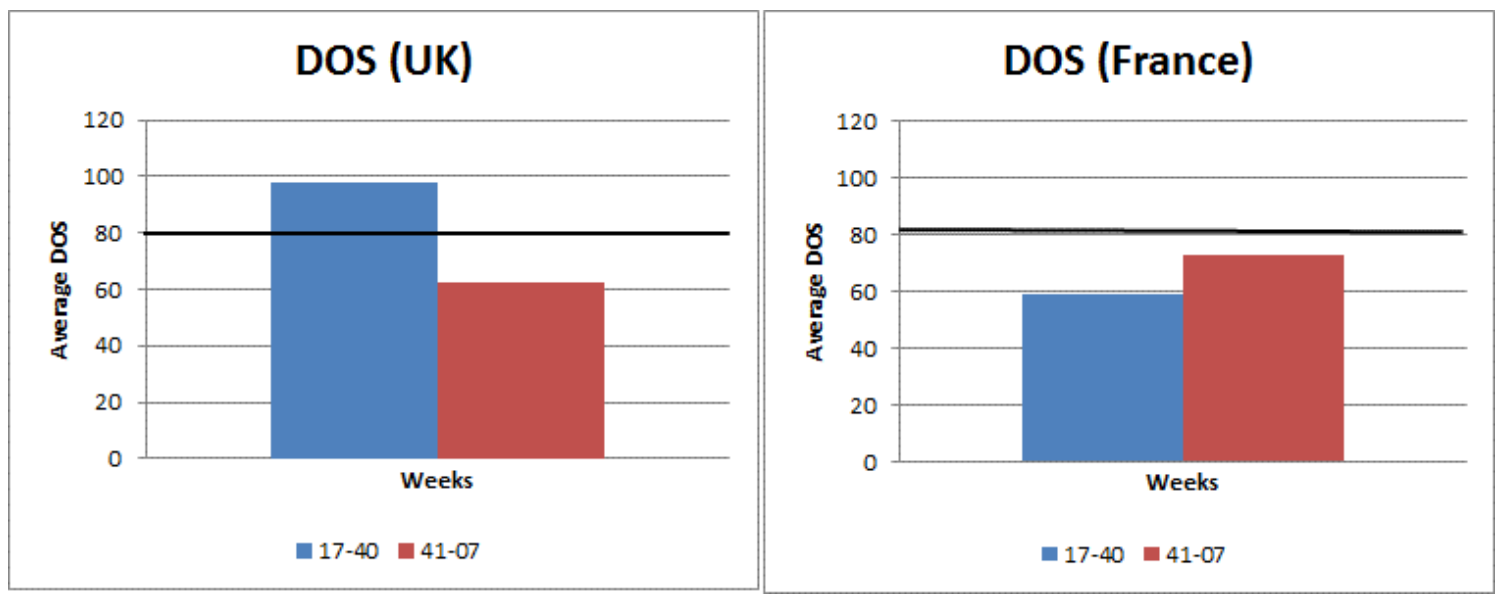

Figure 23: Weighted average DOS comparison in country level.

To be sure that activation data driven execution works in all dimensions, customer level information is included to the thesis as well. Customers' inventory and demand data was presented for two earlier mentioned sales areas. Customers are named randomly with a letter to keep their privacy. Customer inventory levels are not steered by activation data, but because country levels are it does reflect straight to the customer level as well. Nowadays also local logistics department are able to use activation data to support their supply allocation decisions which could accentuate benefits of new supply chain control point.

In figure 24 can be seen how healthy inventory share is increased almost in every customer. There are some tiny exceptions but generally healthy inventory share has been increased from $27 \%$ to $41 \%$ which means that it was almost doubled. This will affect tremendously to the cost of carrying inventory due to lower inventory levels. 


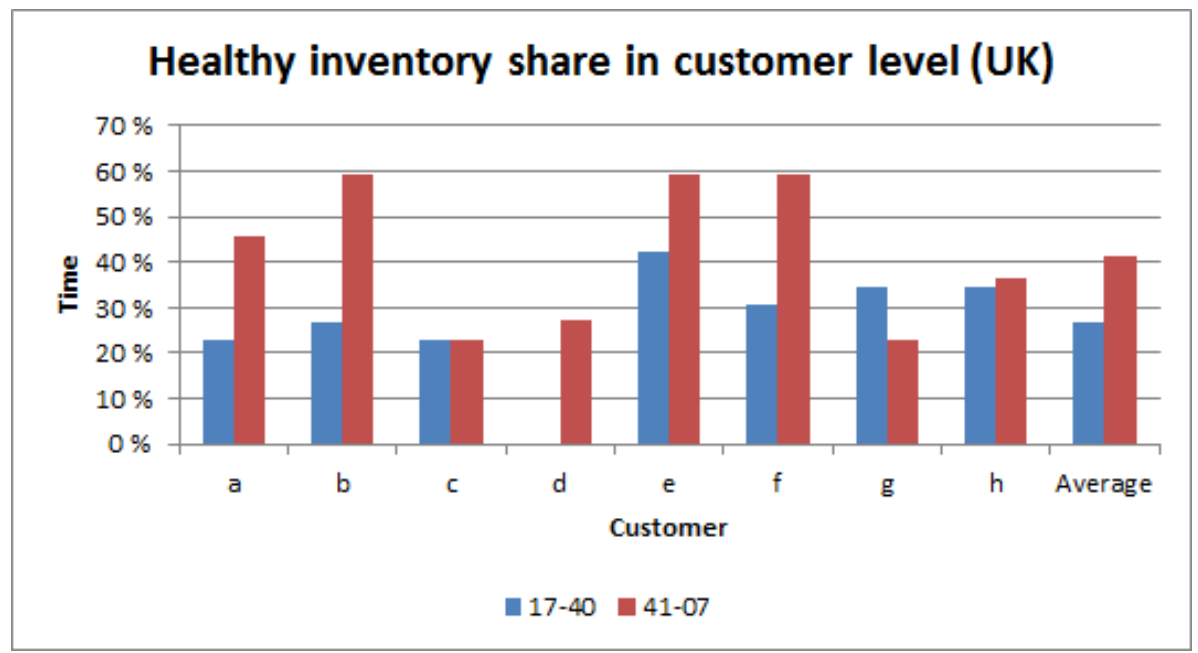

Figure 24: Healthy inventory share comparison in customer level (UK).

In France same kind of development of healthy inventory share can be seen as in the UK. There are also a few exceptions where healthy inventory share has been decreased from earlier time frame compared to activation data driven time frame. The average share has been increased from $22 \%$ to $35 \%$ which is more than 50 percent change. See figure 25 . Also one interesting point is that one customer has $0 \%$ healthy inventory share with old way of working and by using activation data in steering of supply chain, share increased from $0 \%$ to $77 \%$ which is a huge improvement.

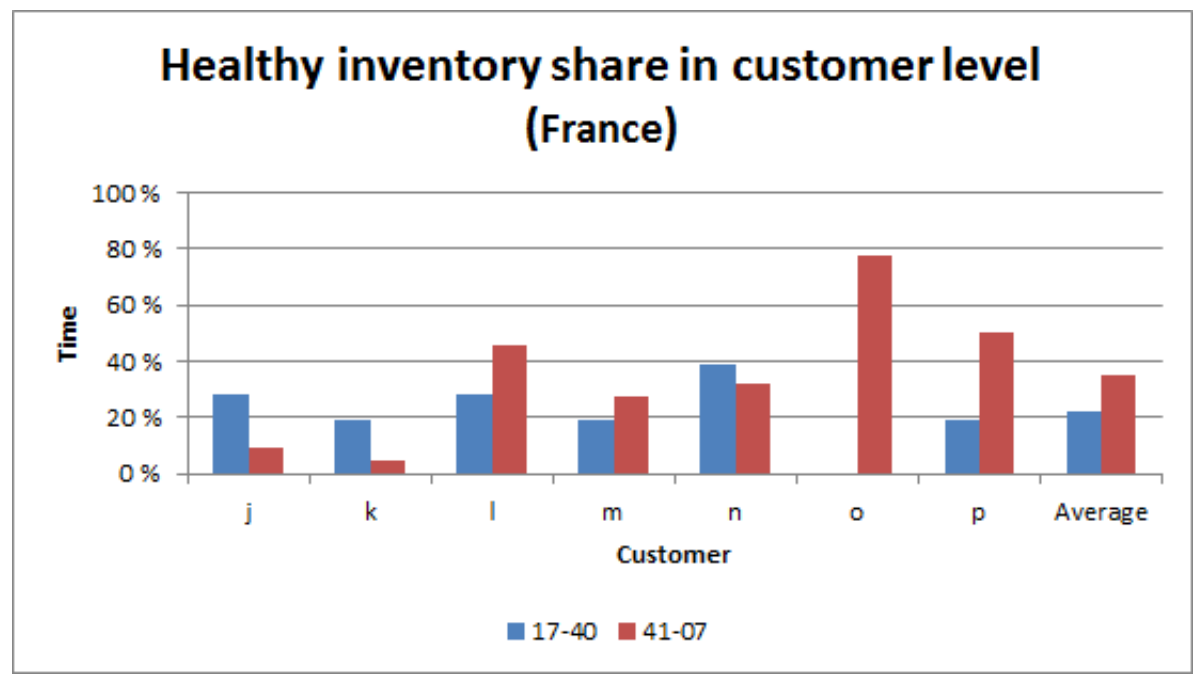

Figure 25: Healthy inventory share comparison in customer level (France). 
Activation data has the following influences to supply chain based on case study A:

- Inventory levels are more stable when activation data is used as a new control point in supply chain. In other words it decreases the bullwhip effect which reduce total costs due to more stable production and demand picture to suppliers

- By using real time demand data DOS levels can be lower without risking availability. This means that the company did not have to invest so much money to finished goods and in the same time availability was good in point of sales

- Healthy inventory share can be tripled in some countries by increasing demand visibility

- With the new control point supply chain is more responsive which is extremely important in uncertain market environments where demand fluctuates and component lead times are long.

\subsection{Product B}

In this chapter the purpose is to analyze how activation data driven supply chain has changed inventory and DOS levels for product B in different levels i.e. customer, area and region level. The researched time frame has been also divided into three different sections as earlier. DOS targets are a bit different than for product A. As max DOS has been set for 90 days, target DOS for 70 days and min DOS for 50 days.

Inventory versus demand data for product B in Europe is illustrated in figure 26. There can be seen how inventory volumes have developed against demand (activation). During RU phase and "old way" both curves increases almost identically, but in the activation data driven section it is easy to notice that even when demand has been very stable, inventory level was decreased due to improved demand visibility. A typical seasonality mixes a bit, but it still is easy to state that with new supply chain control point it is possible to stabilize DOS levels and reduce the cost of inventory carrying. 


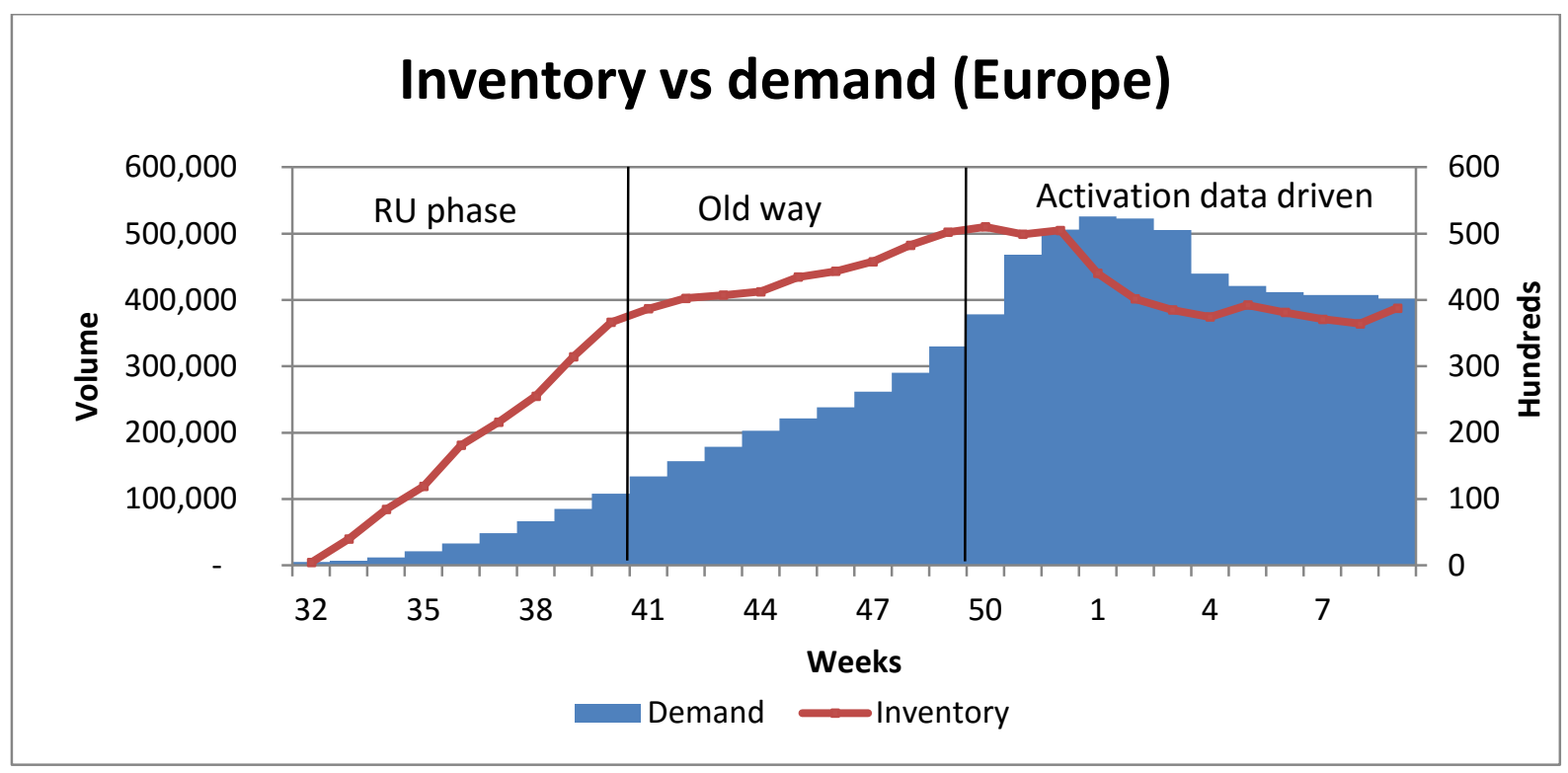

Figure 26: Historical inventory vs demand data for product B in Europe.

Benefits of activation data utilization can be seen crystal clear in this figure, because if DOS will be calculated, it has been very stable from week 4 onwards i.e. 70 days which is very close to the target level. From week 32 to week 49 one can observe same characteristics than for product A due to RU phase and "old way" of working. For example, a big inventory increase which was more than actual demand and need. Also product B has a little bit fewer than $100 \%$ of coverage which is scaled up to $100 \%$ and it has same activation delay as product $\mathrm{A}$.

DOS level development has been illustrated in figure 27. Figure include DOS level information from RU phase to activation data driven phase. Time frame is dived to three different parts as earlier is noted. DOS has decreased for almost the whole time frame from the beginning of sales start to the beginning of activation data driven phase. One reason for this long period of decreasing DOS was product B's hard sales start where sellout was not as good as planned. Due to this fact it can be noted that gap between DOS level in different time periods should be smaller if sales start had gone better. Still it can be seen that DOS is in target level from week 3 onwards which supports the hypothesis of this thesis. All in all it is clear that with activation data driven supply chain it is possible to achieve lower DOS levels without facing stock outs or overstocks. 


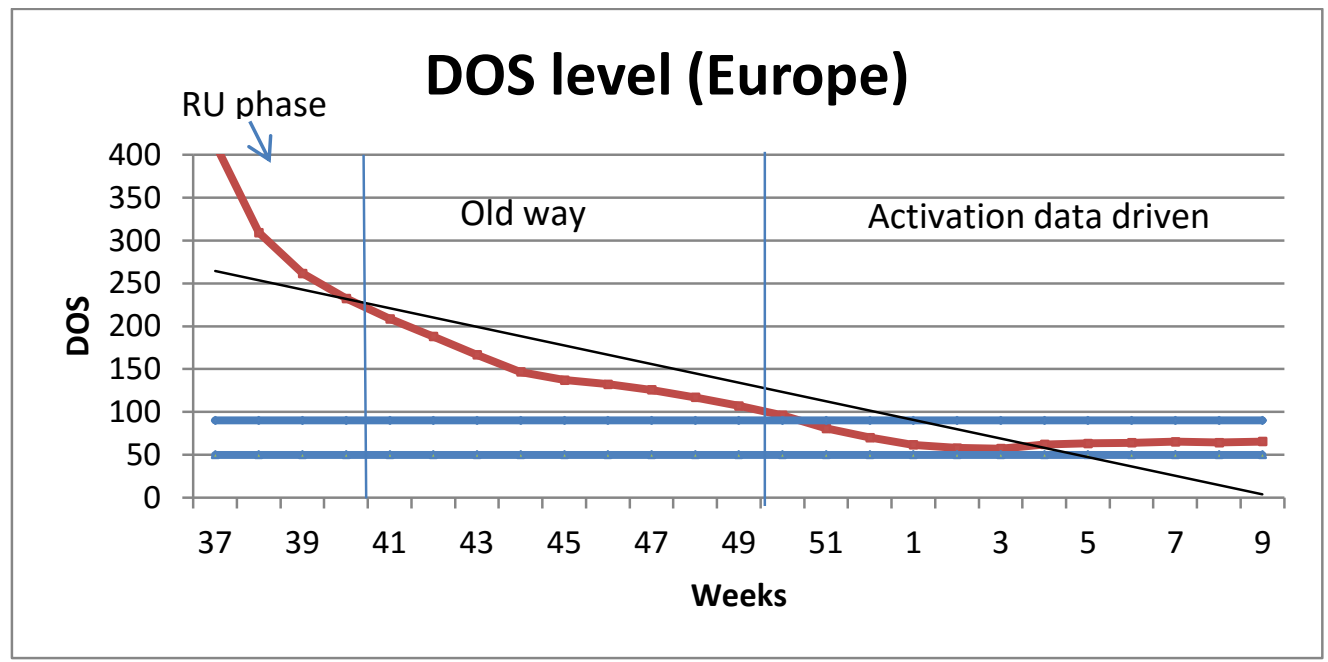

Figure 27: Days-of-supply level for product B in Europe.

Healthy inventory level is defined the following way for product B. In the case that DOS is under 50 days or over 90 days then it can be said that inventory is unhealthy i.e. Inventory is in healthy level between 50 and 90 days. In perfect situation DOS should be 70 days as it is defined as the target level. Figure 28 applies same legends and titles as product $\mathrm{A}$. In other words different markets are presented on $\mathrm{X}$-axis and on $\mathrm{Y}$-axis is illustrated how many percent of time inventory has been in healthy level.

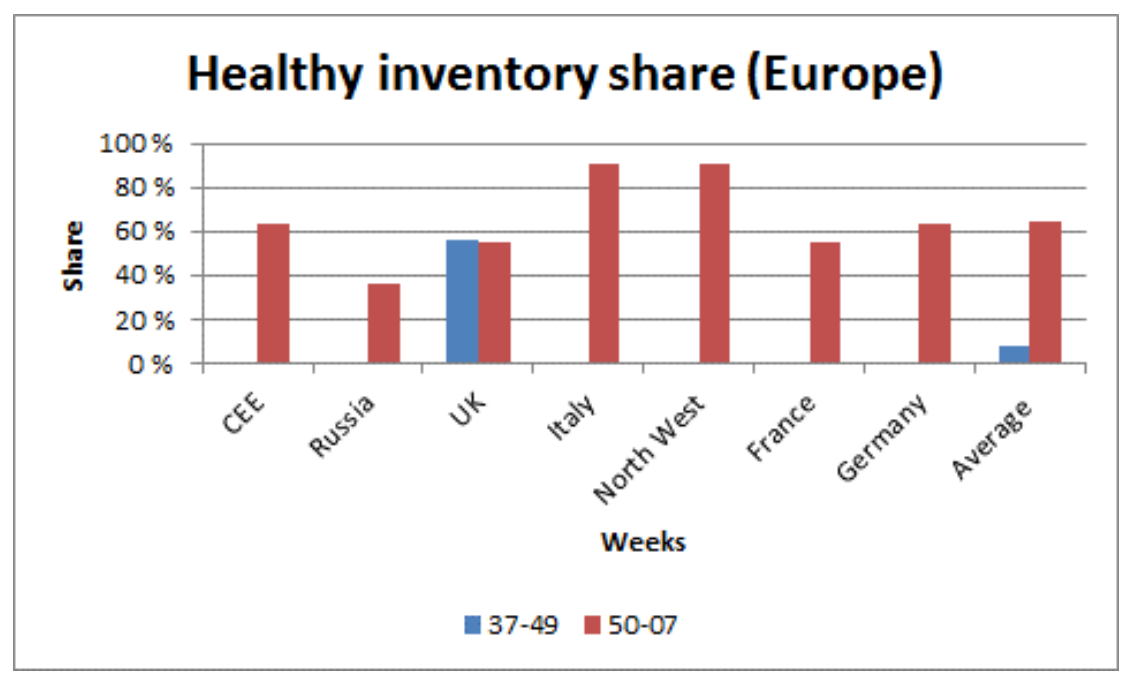

Figure 28: Healthy inventory levels for product B in Europe. 
From figure it can be seen that the average healthy inventory share is increased from $8 \%$ to $65 \%$ which is a huge improvement. In other words this reduces the cost of inventory carrying dramatically. One reason for this huge improvement is that the sales start of product was a bit sticky and there was radical oversupply due to lack of demand data. Only UK customers were selling these products moderately which explain why it was the only country who had decently healthy inventory share between P10-P11.

Below is presented how DOS level has changed after demand activation data utilization. RU phase is removed from comparison and DOS is a weighted average by shipped volumes. DOS comparison shows clearly how big the change has been from old way to activation driven supply chain. DOS has decreased from 160 days to 71 days which is extremely good because 70 days is the targeted DOS. In other words it can be noted that stable target DOS level is possible to achieve with improved demand visibility.

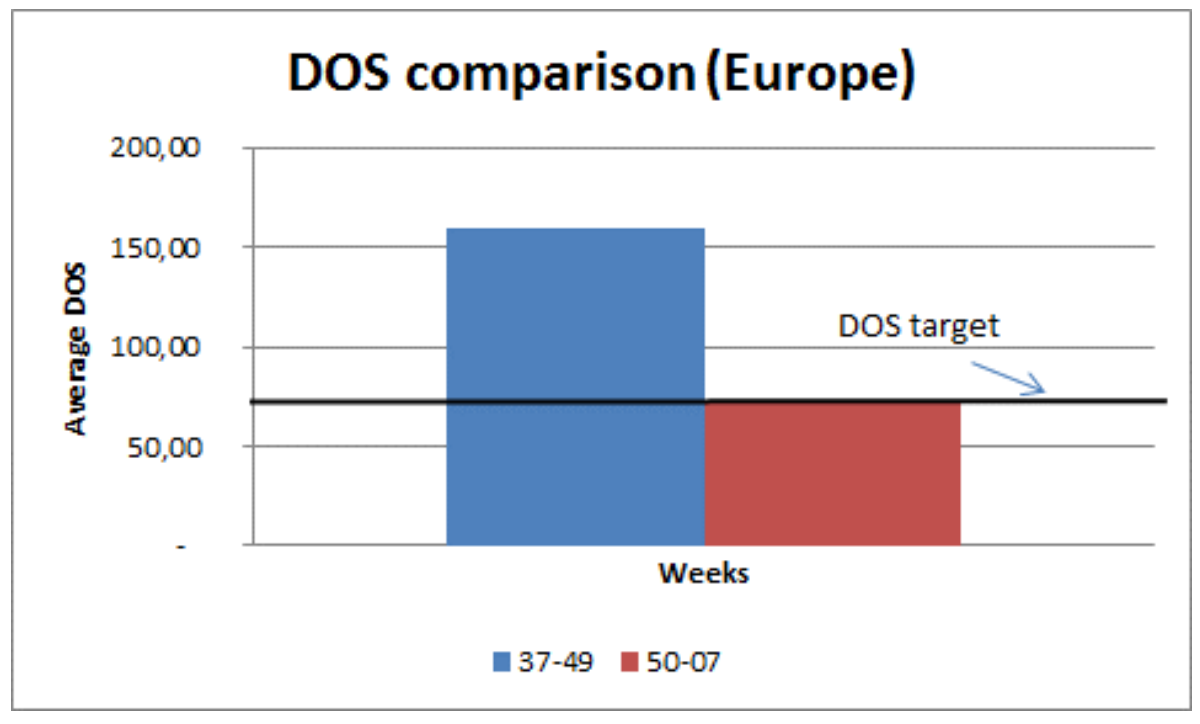

Figure 29: Weighted average DOS comparison in Europe.

In figure 30 inventory status for product B in Europe is presented. Figure has been built same way as earlier for product A i.e. red color illustrates how many percentage is overstocked, blue color illustrates how many percentage of inventory is healthy and green color illustrates how many percentage is understock. In Ru phase it is typical that factory ships more volumes to the channel than what is the actual demand. Like for this product a bit more than $40 \%$ of inventory was overstock due to channel fill and poor sales start of 
product B. Also in the "old way" section amount of overstock was too big due to weak sell-out and inaccurate plans. The situation improved a lot in activation data driven section where it can be seen that most of the inventory was in blue except for time period from week 52 to week 2. This short peak can be explained with Christmas sales and delay of activation data. Based on inventory status of product B it can be noted that with activation data driven supply chain it is possible to keep lower inventory levels and release equity to other purposes.

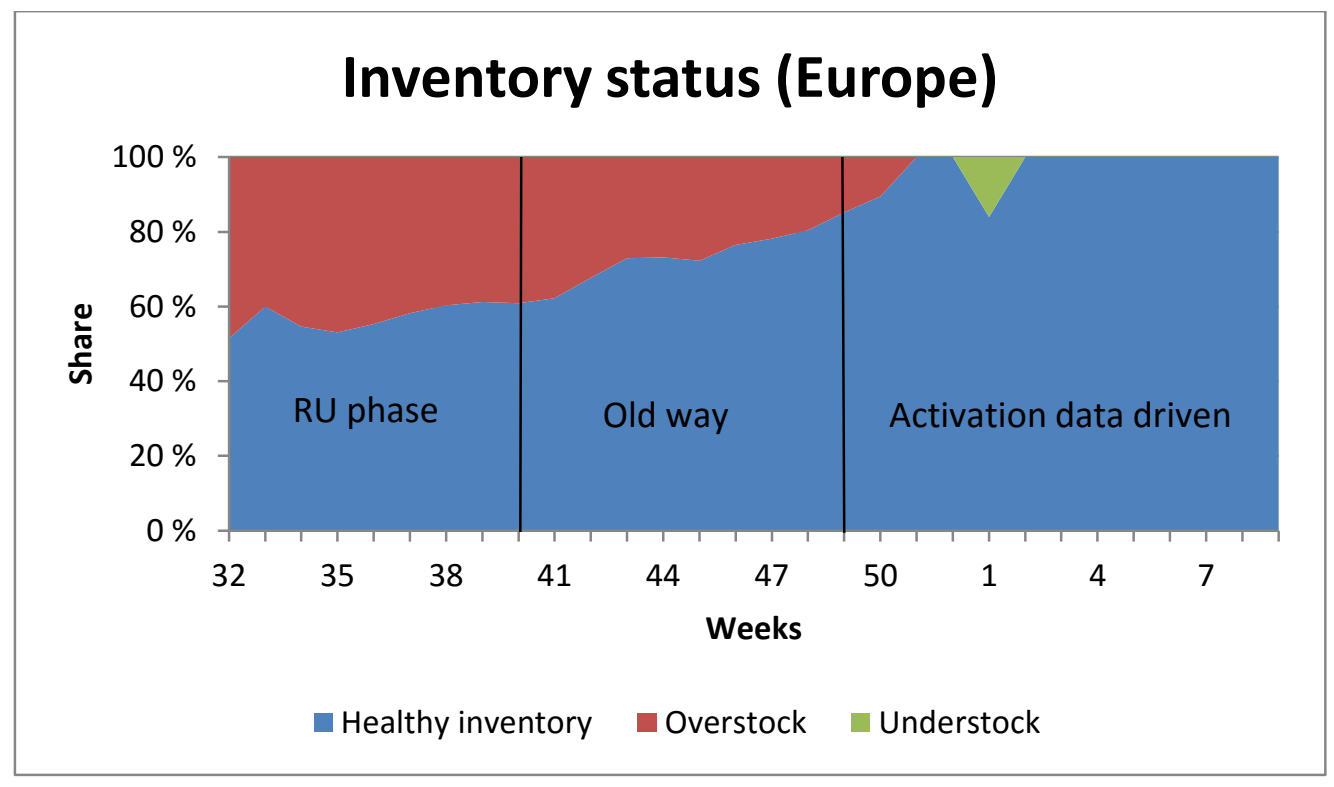

Figure 30: Inventory status for product B in Europe.

By reviewing inventory versus demand for product B in UK it is easy to notice how activation data driven supply chain has kept inventory volumes same level as in "old way" section even when demand has increased 50\%. For example in week 9 inventory was 50000 pieces and 7500 activations per week and in week 49 inventory was the same level as in week 9 but demand was only about 4900 activations per week. In other words DOS level had decreased from 71 days to 46 days. It is also important to see how stable the increase of demand has been from week 34 to week 50 and still inventory level fluctuated quite much due to inaccurate forecasts and lack of demand visibility. According to the data from figure 31 it can be stated that there is a clear connection between improved demand visibility and DOS levels. 


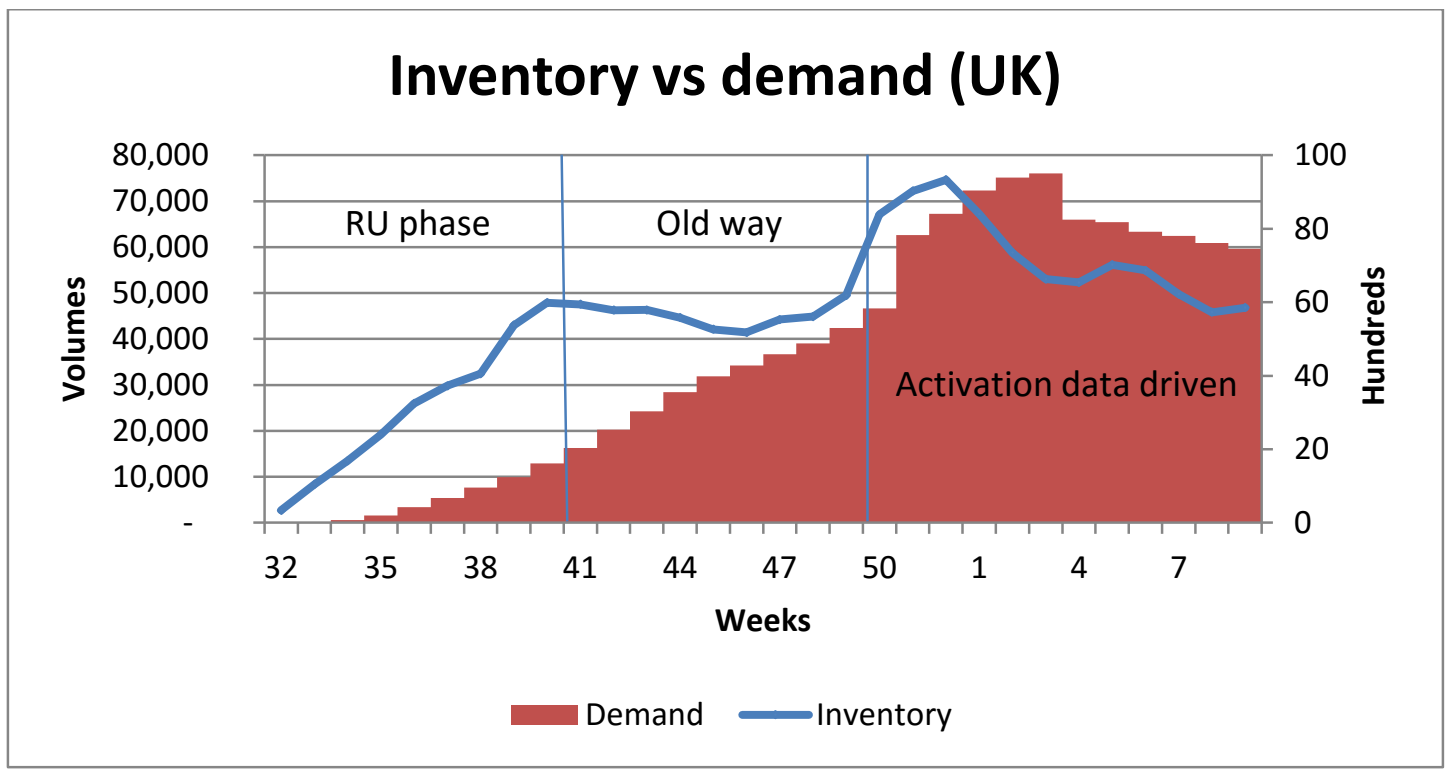

Figure 31: Historical inventory vs demand data for product B in UK.

The channel fill has been much more aggressive in France for product B than it was in UK. According to figure 32, inventory level and activations has developed differentially. Inventory level increased dramatically in the sales start while activations increased quite slowly. In the beginning of "old way" section inventory stabilized to 70000 pieces level even when demand increased slowly. Before activation data driven phase DOS was quit high but by utilizing improved demand data, inventories were decreased significantly to 58 days which is quite near to the target level. It is also good to note that time period from week 52 to week 6 is very typical seasonality due to Christmas sale and activation delay. 


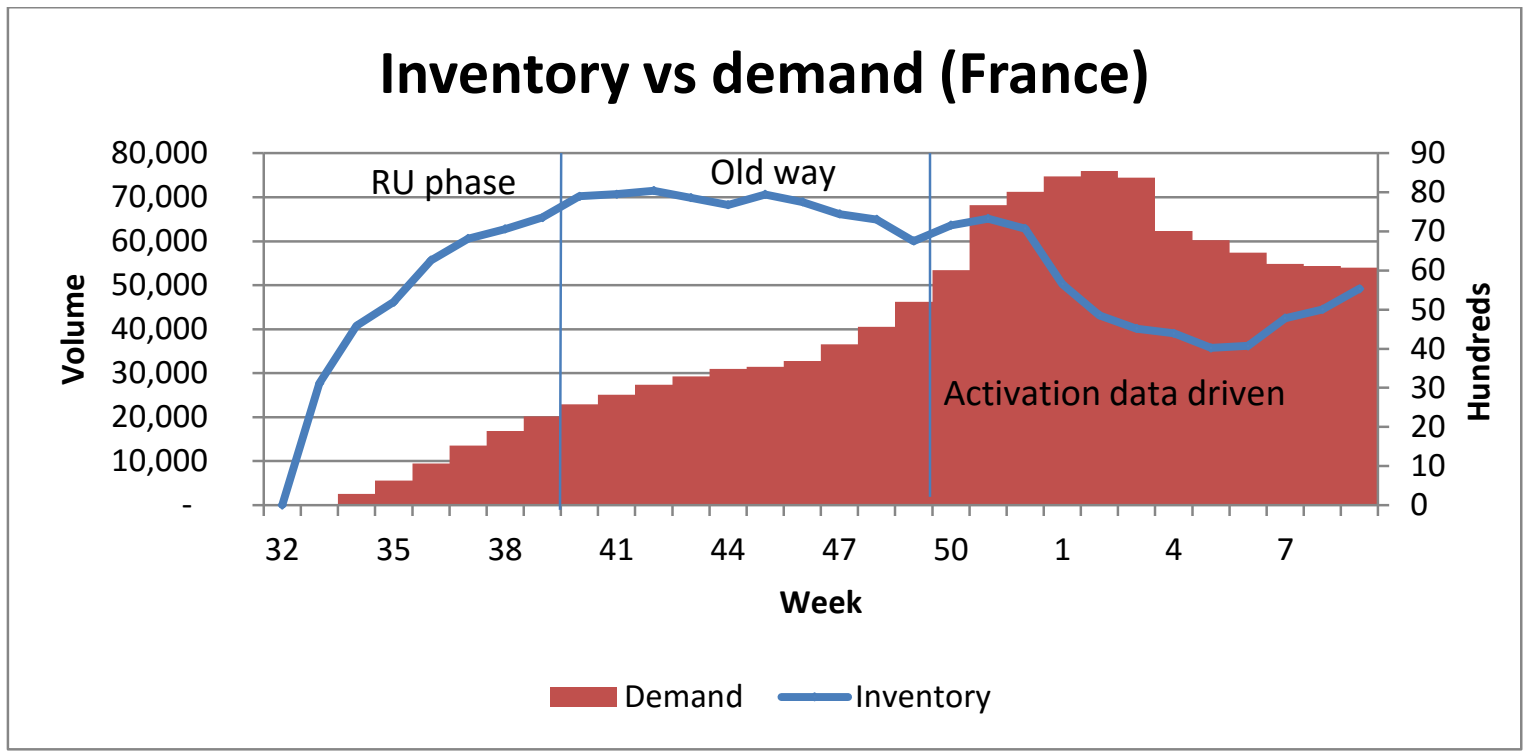

Figure 32: Historical inventory vs demand data for product B in France.

By looking the healthy inventory share for product B in UK and France it can be seen that average healthy inventory share has increased from $33 \%$ to $38 \%$ which is about 18 percent. Just looking the average measure does not tell the whole truth as this measure is not weighted by shipped volume. Taking into account that healthy inventory share of France has been $0 \%$ between $\mathrm{P} 10$ and $\mathrm{P} 11$ and it is increased to $55 \%$ after P12. This is a significant improvement in country level. Healthy share of UK has decreased only $1 \%$ which can be explained with better forecasts and sell-out. In figure 33 United Kingdom and Ireland are also presented separately even of the one sales unit in the eyes of the case company. Finally, it can be noted that in country level there has happened a remarkable improvement in terms of healthy channel inventory. 


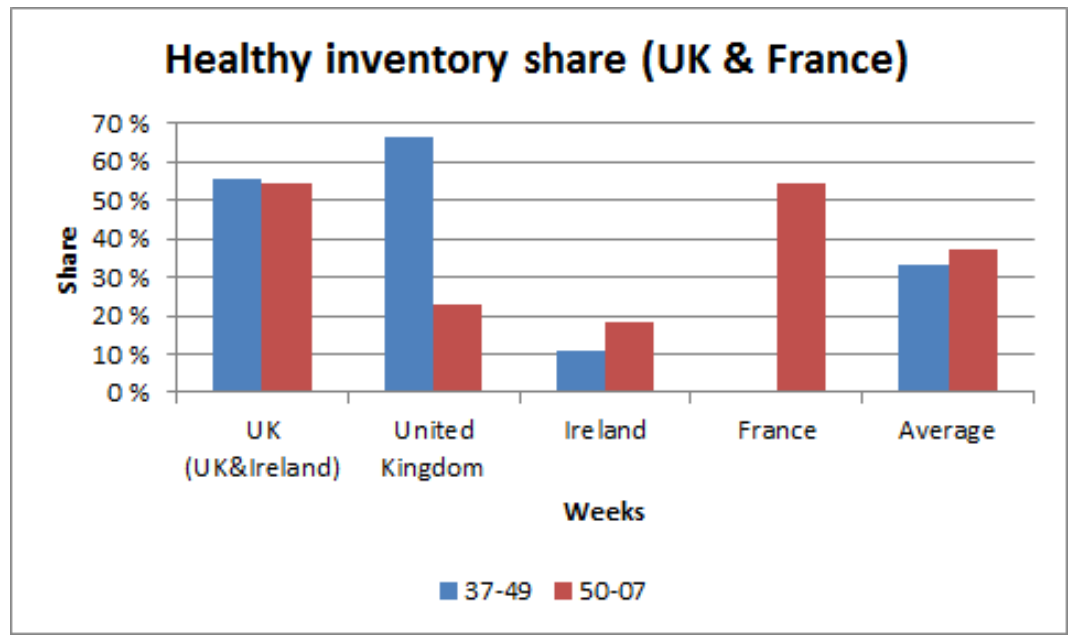

Figure 33: Healthy inventory share comparison for product $B$.

Below is presented a DOS comparison in UK \& France where it can be seen how activation data driven supply chain has affected DOS levels in different countries. DOS has been weighted by shipped volumes to give as reliable result as possible. Comparison shows crystal clearly how DOS reduced from 115 days to 55 days in UK and from 148 days to 53 days in France. According to figure 34 inventories have been kept quite near the target level to minimize inventory levels and still the case company was able to guarantee availability for UK and France. The sticky sales start skews a bit DOS comparison between different time periods but still benefits of activation data can't be denied.

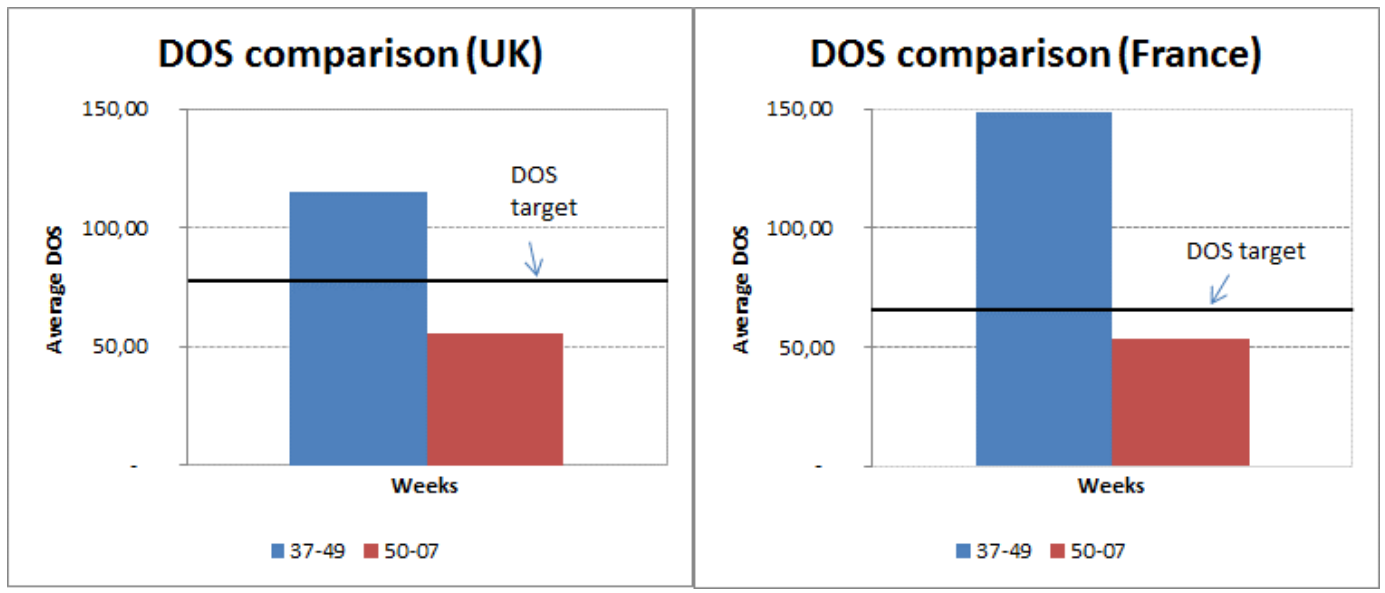

Figure 34: Weighted average DOS comparison in country level. 
Healthy inventory share in customer level has been taken into account for product B as well to be sure that activation data driven execution works in all dimensions. As earlier is mentioned, Activation data was not used in customer level execution, but its benefits still flow from Europe and area levels to customer level. Figure 35 is built same way as for product A.

From figure 35 can be seen how healthy inventory shares have fluctuated in different customers in UK due to lack of demand visibility and inventory level steering. From October to March customer's inventories were steered with historical sell-in and forecasts which explains why healthy share has remained almost unchangeable during the whole time horizon. All in all it can be noted that local logistic team has kept inventories quite good level even when activation data was not available for them.

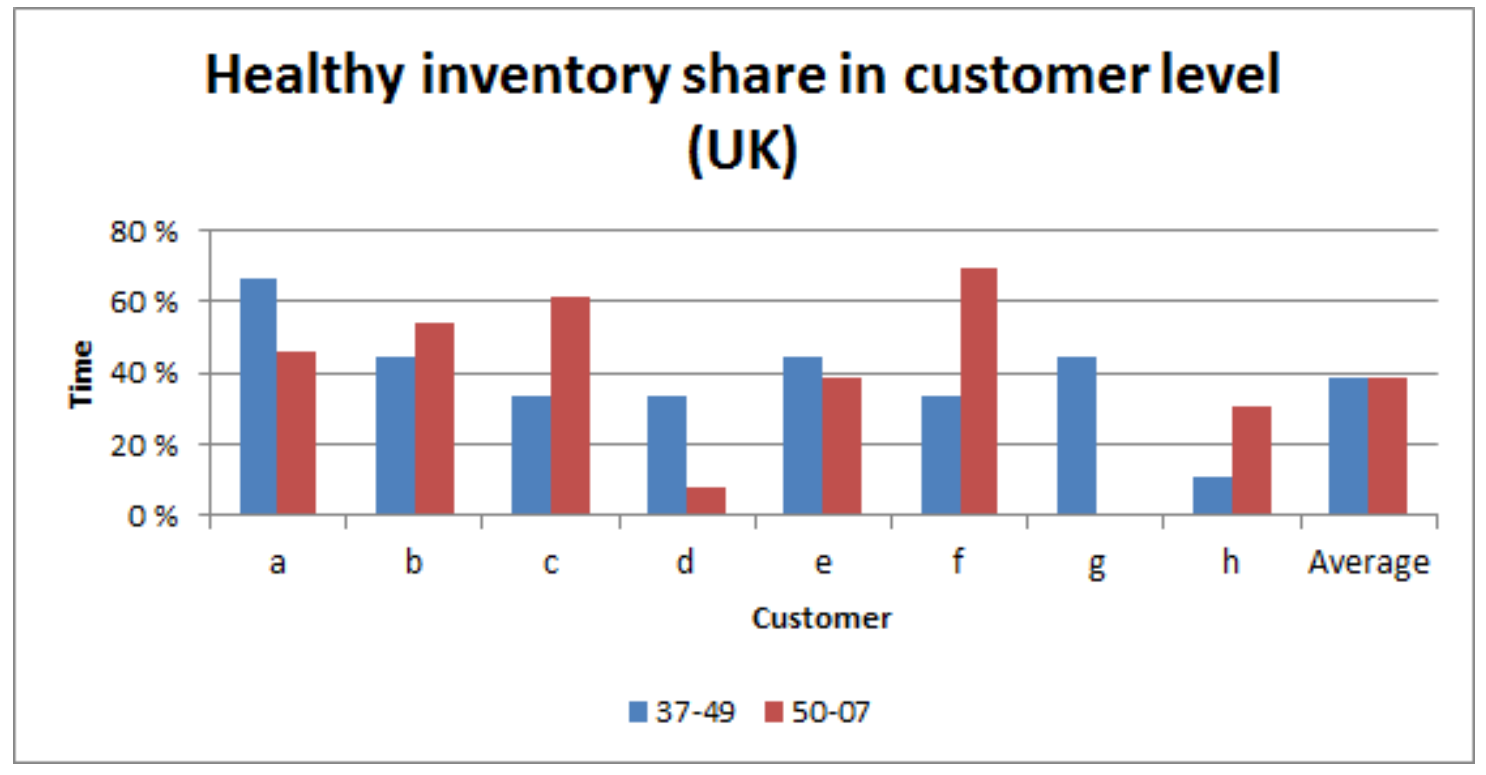

Figure 35: Healthy inventory share comparison in customer level (UK).

In France customer level healthy inventory share development has been a bit different than in UK. Only two customers have had at least small healthy inventory share from P10 to P11. Other five customers were at the same time at unhealthy level and after the activation data driven execution was implemented healthy inventory share increased significantly. In other words average share has been increased from $18 \%$ to $38 \%$ i.e. increase was over $100 \%$. According to this information, the case company reduced 
remarkably stock-out and overstock risks during the time horizon due to a healthier channel inventory. It is also interesting to see that one customer was not able to reach healthy inventory share even once during October-February. One reason might be that the customer was all the time overstocked to be sure of availability as it is the most important customer in France.

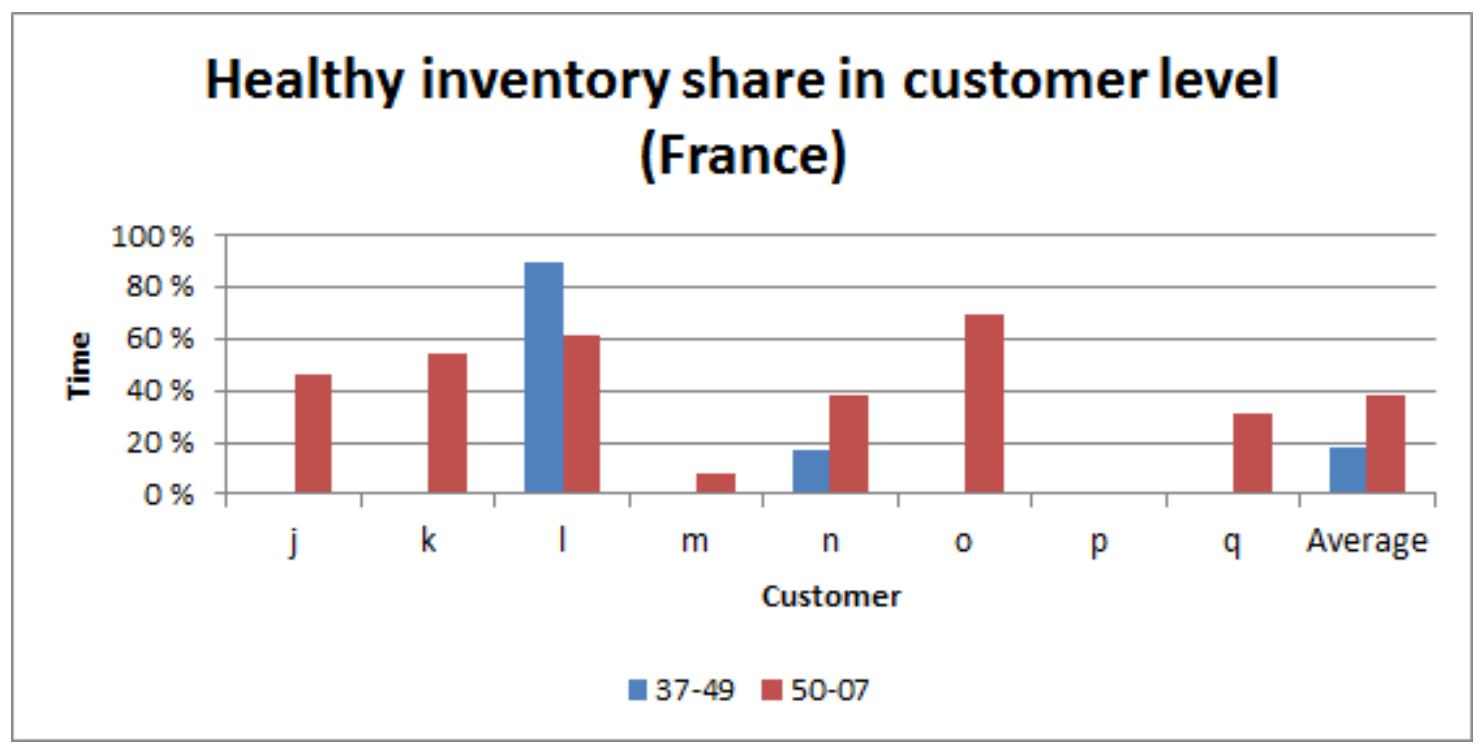

Figure 36: Healthy inventory share comparison in customer level (France).

Activation data has the following influences to supply chain based on case study B:

- With new supply chain control point is possible to stabilize DOS levels and reduce the cost of inventory carrying. In other words the bullwhip effect is slighter

- With activation data driven supply chain is possible to achieve lower DOS levels without facing stock outs or overstocks. Total DOS levels decreased by $50 \%$ and no stock outs were noticed during the time horizon

- Demand visibility improved which makes supply chain more responsive

- Benefits were much more obvious than in case study A 


\section{Conclusions}

In this final chapter, the thesis is concluded by first shortly summarizing the empirical part of the study, then contribution to existing knowledge is presented, after that is highlighted the benefits and results of healthy inventory and finally suggestions for future research opportunities and actions. Summary of the theoretical part is excluded from this chapter as it is already discussed in chapter 3 .

\subsection{Main findings}

This study aimed to offer analysis for the case company about how increased demand visibility has impacted to their inventories in Europe. Before this analysis the case company did not have any concrete proof how the new steering point of supply chain had impacted their business. The only thing what has been indicating that the new control point might work was the smaller number of escalations from countries. In order to provide reliability to the analysis it has been done on customer, country and region level for two different products that sell enough to guarantee reliable research results. Next, the key findings from the case study research are presented.

A successful demand-supply balancing is one essential component to succeed in FMCG business. There are various ways to optimize demand-supply balance. In this thesis, the emphasis has been set for better information utilization in supply chain network. By sharing information of real demand so that all the players in the chain are working with same demand and supply numbers, it is possible to achieve higher levels of on-the-self availability and lower inventories. It can be noted as well that a flexible and responsive supply chain helps a company mitigate risks associated with uncertainty in demand.

In case when forecasted demand is over estimated from the actual demand it can be called an oversupply situation. To mitigate these situations the case company has started to gather activation data from their products and based on that information they have the capability to steer extra supply quickly to markets where it is really needed and not just forecasted. 
Based on the case study findings, the new control point in supply chain allows utilizing supply smarter than before due to real time demand visibility. With better supply steering it is possible to decrease inventory levels without risking availability in point of sale. In other words, with real time demand data it is easier to achieve demand-supply balance. The findings related to lower channel inventories and improved supply steering are covered wider in next sub-chapter.

From the case study it can be noted as well how bullwhip effect has decreased due to better information flow in the supply chain. This can be seen in more stable inventory levels and supply inside Europe. Because sell-out was usually stable for all customers, supply was steered based on real demand instead of order creation date.

\subsection{Healthy inventory}

The key issue of the case company's supply chain management is to keep costs low and in the same time maximize availability. From the case company's supply chain point of view healthy inventory is one of the key priorities in terms of cost reduction. The term of healthy inventory is already defined earlier in this thesis and results of empirical study of healthy inventory are presented in chapter 5. This sub-chapter focuses in illustrating achieved savings due to better supply utilization in the focus market.

In the past main focus was sell-in and order fulfillment but with real time activation data focus can be moved to health inventory and supply optimization based on real time activation data. With this new focus significant cost savings can be achieved by decreasing restricted capital in supply chain and reducing obsolescence in channel.

The cost analysis has been done for products A and B. In the analysis it can be seen that with the new way of working it is possible to decrease restricted capital in the supply chain by $66,7 \mathrm{M} € /$ year. In other words the case company can use this amount of money to other investments. In case the money is loaned from a bank and average loan rate is $6 \%$ it causes about $4 \mathrm{M} €$ interests/year for these two products in total. The restricted capital decrease can be calculated with a formula that is presented below: 
Yearly savings can be calculated with the formula below:

Restricted capital decrease $x$ loan rate $=$ yearly savings

Restricted capital decreases and yearly savings are presented in table 4 .

Table 4: Cost savings and end results by product.

\begin{tabular}{|c|c|c|c|c|}
\hline \multicolumn{5}{|c|}{ Product A } \\
\hline DOS decrease (days) & Activations (pcs) & Price (€) & Value (€) & Savings (€) \\
\hline 29 & 12612 & 80 & 2959840 & 1755590 \\
\hline
\end{tabular}

\begin{tabular}{|c|c|c|c|c|}
\hline \multicolumn{5}{|c|}{ Product B } \\
\hline DOS decrease (days) & Activations (pcs) & Price (€) & Value (€) & Savings (€) \\
\hline 88 & 3713 & 115 & 37471824 & 2248309 \\
\hline
\end{tabular}

With these calculations it is easy to make conclusions how much the new control point can reduce costs and restricted capital for the case company. For example if a portfolio includes 20 products, cost savings might be more than $40 \mathrm{M} € /$ year and on top of that will come indirect savings i.e. employees use less time for escalations and email exchanges. The benefits of new way of working become emphasized once products are constrained and all customers can be kept "alive" with proper supply utilization. In case some customers go to a stock-out situation they might de-range the product due to poor availability which affects life cycle volumes and company's reputations as a reliable supplier in the long run.

\subsection{Contribution to existing knowledge}

This thesis contributes to an almost non-existing area of research, which caused a bit of a challenge in outlining the scope of literature review. Even though wide variety of literature was searched there were not any mentions about activation data utilization in supply chain optimization. There might be couple of major reasons, first of all in the market there are only a few products that can "speak" i.e. are connected same way to the internet as the products of the case company. I believe that this will change in the future when internet of things develops from what it is now. Secondly activation data is so new thing that 
companies do not know yet how to use it or they want to keep information inside of the company.

\subsection{Future research opportunities}

The limitations of this thesis are mainly focused to the empirical study. Due to limited time, there are many details that can be still investigated. For example all countries can't be managed with the same way as material channels and lead times are different. In the future DOS targets should be defined for all seasonality by country in all life cycle phases. When the empirical study was made, countries were not able to balance their supply based on the activation data. At the moment they are able to do it and probably DOS targets can be decreased due to increased information in supply chain.

In the future one should research how this increased information can be used or integrated to sell-in planning process that where device activations and all tier channel inventory are taken into account. At the moment sell-in is not managed with activation data and it is leading to poor planning accuracy which could result into:

- Excess inventory

- Liabilities in the supply chain for case company

- loss of sales

- Ties up customer working capital

- Additional sell-through support $\rightarrow$ market price drop which will hurt customer profitability 


\section{REFERENCES}

Aberdeen group, 2006, Demand management in consumer industries, Available at: http://www.smartcorp.com/pdf/Demand_Mgmt_Benchmark_Rpt.pdf(accessed 13.01.2014)

Agarwal, A. \& Shankar, R. \& Tiwari, M.K. 2006. Modeling agility of supply chain. Industrial Marketing Management, Vol 36, pp. 443-457.

Aitken, J. \& Christopher, M. \& Towill, D., 2002, Understanding, Implementing and Exploiting Agility and Leanness, International Journal of Logistics Researh \& Applications, Vol 5, pp. 59-74.

Bayle, M., 2003, Brand killers, Fortune, pp. 51-56.

Berry, D. \& Naim, Quantifying the relative improvements of redesign strategies in a P.C. supply chain, International Journal of production economics, Vol. 46-47, pp. 181-196

Chen et al., 2000, Quantifying the Bullwhip Effect in a Simple Supply Chain: The Impact of Forecasting, Lead Times and Information, Management Science, Vol. 46, pp. 436-443

Chopra, S. \& Meindl, P., 2010, Supply Chain Management, Pearson Education Limited, New Jersey, 519 p.

Christopher, M., 2011, Logistics \& Supply Chain Management, Pearson Education Limited, London, 268 p.

Christopher, M \& Lowson, R. \& Peck, H., 2004, Creating Agile Supply Chains in the Fashion Industry, International Journal of Retail and Distribution Management, Vol. 32, pp. 367-376.

Christopher, M. \& Towil, D. 2001. An Integrated Model for the Design of Agile Supply Chains. International Journal of Physical Distribution and Logistics Management. Vol 31, pp. 235-246. 
Collin, J., 2003, Selecting the Right Supply Chain for a Customer in Project Business, Helsinki, 213 p.

Cooper, M.C. \& Lambert, D.M.. \& Pagh, J., 1997 Supply Chain Management: More Than a New Name for Logistics. The International Journal of Logistics Management Vol 8, pp. $1-14$.

Corsten, D. \& Gruen, T., 2004, Stock-outs cause walkouts, Harvard Business Review.

Eisenhardt, K. 1989. Building theories from case study research. The Academy of Management Review, 14(4) pp. 532-550.

Fisher, M., 1997, What is the Right Supply Chain for Your Product, Harward Business Review, Vol 75, No. 2, pp.105-116.

Fliedner, D. \& Vokurka, R., J., 1997, Agility: Competitive weapon of the 1990s and beyond?, Production and Inventory Management Journal, Vol. 38, pp.19-24.

Goldsby, T. \& Griffis, S \& Roath, A., 2006, Modelling Lean, Agile and Leagile Supply Chain, Journal of Business Logistics, Vol. 27, No. 1, pp 57-80

Grant D. \& Lambert, D. \& Ellram, L., 2006, Fundamentals of Logistics Management, European Edition, McGraw-Hill, New York, 436 p.

Harrison, A. \& van Hoek, R., 2008, Logistics Management and Strategy, Pearson Education Limited, England, 316 p.

Hoover, W.E. \& Eloranta, E. \& Holmström, J. \& Huttunen, K., 2001.Managing the Demand-Supply Chain - Value Innovations for Customer Satisfaction. John Wiley \& Sons, Inc., New York, 257 p.

Hopp, W. J. \& Spearman, M. L., 2001, Factory Physics - Foundations of Manufacturing Management, Irwin/McGraw-Hill, New York, 698 p. 
Huan, S.H. \& Sheoran, S.K. \& Wang, G., 2004, A review and analysis of Supply Chain operations reference (SCOR) model, Supply Chain Management: An International Journal, 9 (1), pp.23-29.

Vitasek, K., 2006, Supply Chain Terminology and Glossary, available at http://www.logisticsservicelocator.com/resources/glossary03.pdf (accessed 10.01.2014).

Kent, D. \& Attri, H., 2007, SCOR, Lean and Six Sigma - Supply Chain Synergy, available at https://supply-chain.org/f/Supply\%20Chain\%20Synergy.pdf (accessed 15.01.2014)

Leanyourcompany.com, $\quad$ accessed $\quad 28.01 \quad \rightarrow$ http://www.leanyourcompany.com/analyze/Supply-Chain-Responsiveness-matrix.asp

Lee, H., 2004, The Triple-A Supply Chain, Harvard Business Review, Vol. 82, No. 10, pp. 102-112.

Lee, H. \& Padmanabhan, V. \& Whang, S., 1997, Information Distortion in a Supply Chain: The Bullwhip Effect, Management Science, Vol. 43, pp. 546-557.

Mason-Jones, R. \& Naylor, R. \& Towil, D.R., 2000, Engineering the Leagile supply Chain, International Journal of Agile Manufacturing Systems, Vol 2, pp. 54-61.

Nokia Corporation, 2009, Supply Chain Management Practices at Nokia Corporation, 14p.

Ohmae, R., 1982, The Mind of the Strategist - The art of the Japanese Business, McGrawHill, United States of America, 304 p.

Ross, D., 1998, Competing Through Supply Chain Management - Creating Market Winning Strategies Through Supply Chain Partnerships, New York: Chapman \& Hall, $365 \mathrm{p}$.

Shapiro, J.F., 2001, Modeling the Supply Chain, Thomson Learning Inc., United States of America, $586 \mathrm{p}$.

Sharifi, H. \& Ismaila, H. \& Qiua, J. \& Tavani, S., 2013, Supply chain strategy and its impacts on product and market growth strategies: A case study of SMEs, International Journal of Production Economics, Vol 145, pp. 397-408. 
Simchi-Levy, D. \& Kaminsky, P. \& Simchi-Levy, E., 2000, Designing and Managing the Supply Chain, McGraw-Hill, USA, 321 p.

Slack, N. \& Chambers, S. \& Johnston, R., 2010, Operations management, Harlow, Pearson Education limited, United States of America, 686 p.

Stevens, G., 1989. Integrating the supply chain, International Journal of Physical Distribution and Materials Management 19 (1), pp. 3-8.

Taylor \& Brunt, 2001...

Yin, R. 2002. Case Study Research: Design and Methods. $3^{\text {rd }}$ edition. Sage Publications, Inc. 